\title{
Ferritin: An Iron Deficiency Biomarker in Collegiate Female Distance Runners
}

\author{
Ty Bigelow \\ West Virginia University, tb0053@mix.wvu.edu
}

Follow this and additional works at: https://researchrepository.wvu.edu/etd

Part of the Sports Sciences Commons

\section{Recommended Citation}

Bigelow, Ty, "Ferritin: An Iron Deficiency Biomarker in Collegiate Female Distance Runners" (2019). Graduate Theses, Dissertations, and Problem Reports. 3795.

https://researchrepository.wvu.edu/etd/3795

This Thesis is protected by copyright and/or related rights. It has been brought to you by the The Research Repository @ WVU with permission from the rights-holder(s). You are free to use this Thesis in any way that is permitted by the copyright and related rights legislation that applies to your use. For other uses you must obtain permission from the rights-holder(s) directly, unless additional rights are indicated by a Creative Commons license in the record and/ or on the work itself. This Thesis has been accepted for inclusion in WVU Graduate Theses, Dissertations, and Problem Reports collection by an authorized administrator of The Research Repository @ WVU. For more information, please contact researchrepository@mail.wvu.edu. 
Ferritin: An Iron Deficiency Biomarker in Collegiate Female Distance Runners

Ty Bigelow, LAT, ATC

Thesis submitted to the College of Physical Activity and Sport Sciences

At West Virginia University

In partial fulfillment of the requirements for the degree of:

Master of Science in

Athletic Training

Michelle A. Sandrey, PhD, ATC, Chair

Jean L. McCrory, PhD

Brenden Balcik, MD

Department of Sport Sciences

Morgantown, West Virginia

2019

Keywords: ferritin, iron, iron deficiency, performance

(C) 2019 Ty Bigelow 


\section{ABSTRACT \\ Ferritin: An Iron Deficiency Biomarker in Collegiate Female Distance Runners}

\section{Ty Bigelow, LAT, ATC}

Context: Iron deficiency is a concern in distance runners due to the implications that hemoglobin production becomes impaired limiting oxygen uptake and tissue oxidation in the body. Ferritin is a biomarker used to diagnose iron deficiency. The related signs and symptoms of iron deficiency are associated with decreased performance and prolonged recovery. Objective: The purpose of this study was to investigate whether the change in ferritin levels affect measures of performance, measures of recovery, and rate of perceived exertion in female endurance runners. Design: The study was a descriptive longitudinal study. Setting: The study was conducted at a Mid-Atlantic Division I university. Patients or Other Participants: The participants in this study were distance runners on the active track and field roster at a Mid-Atlantic Division I university. Inclusion criteria was any active distance runner on the university women's Cross Country/Track $\&$ Field team. Exclusion criteria was any injury resulting in greater than six months from training in the previous two years. Interventions: All participants completed the self-reported demographic questionnaire to determine participation eligibility, injury history, and iron supplementation history. Each participant completed a post-race questionnaire following each race competed to self-report measures related to performance and recovery. Results of ferritin levels and race times were obtained from existing data. Main Outcome Measures: The dependent variables were ferritin concentrations and the post-race questionnaire scores of RPE, sleep, dietary, hydration, and stress. Results: Ferritin levels were found to decrease in both freshman and upperclassman groups from the previous six and eighteen months of testing, respectively. Ferritin levels preseason and postseason were $50.33 \pm 17.94$ and $46.33 \pm 17.75$, respectively, with no significance in change $\mathrm{F}_{1,8}=1.767, \mathrm{p}=0.220$. Partial correlations indicated moderate relationships between ferritin levels and feeling ill or injured $(r=0.42, p=0.002)$, hours of sleep the previous three nights $(\mathrm{r}=0.315, \mathrm{p}=0.021)$, and rate of perceived exertion $(\mathrm{r}=0.407, \mathrm{p}=0.002)$. Conclusions: Ferritin can be a valuable tool in determining iron status in the body and is associated with several measures of recovery. Regular ferritin testing with other hematological markers provide a comprehensive analysis of factors that influence levels of aerobic capacity. Difference in iron stores have a significant relationship with measures of recovery, thus additional studies should be conducted to further investigate the importance of ferritin levels and confirm the findings of this study. 


\section{ACKNOWLEDGEMENTS}

To God for providing the strength and perseverance to complete this work.

To my committee chair, Dr. Sandrey, for allowing me to research this topic and for supporting me in this ambitious endeavor.

To Dr. McCrory for her willingness to serve on the committee and contributions to this work.

To Dr. Balcik for his willingness to serve on the committee and for his incredible guidance and support as Team Physician allowing me to excel both professionally and academically.

To my family who has supported me for the last 25 years and making unbelievable sacrifices. I would not be where I am today living out my dream without them.

To Allison for her overwhelming support, love, and understanding during this entire process. Challenging and encouraging me daily to do my best work is just one of her remarkable qualities. 


\section{TABLE OF CONTENTS}

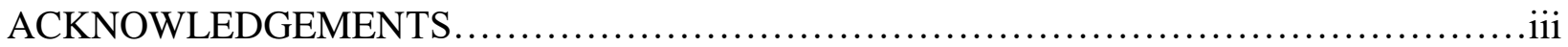

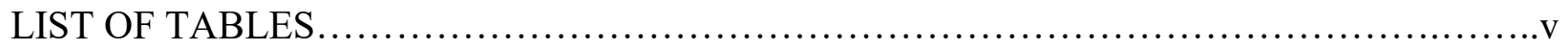

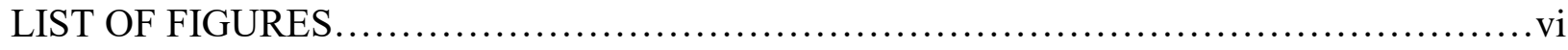

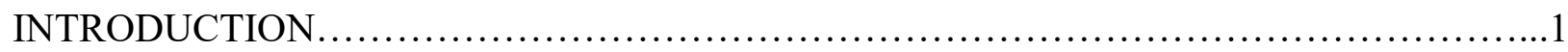

METHODS.............................................................................

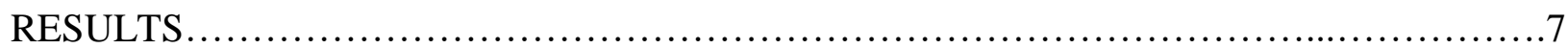

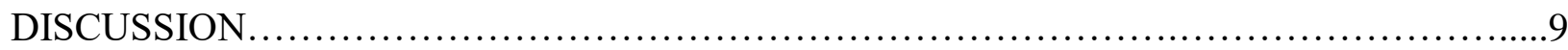

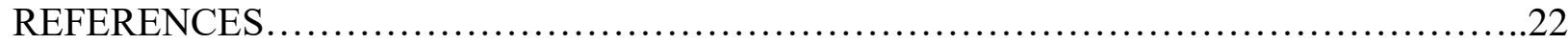

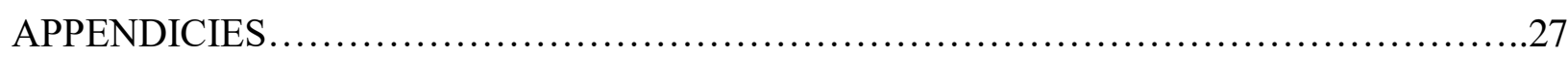

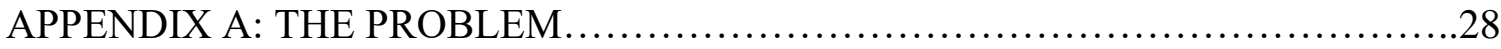

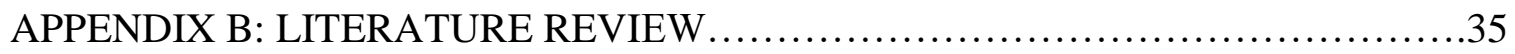

APPENDIX C: ADDITIONAL METHODS ...................................49

APPENDIX D: ADDITIONAL RESULTS ........................................ 55

APPENDIX E: RECOMMENDATIONS FOR FUTURE RESEARCH...............60

ADDITIONAL REFERENCES ......................................................61 


\section{LIST OF TABLES}

Table C1. Consent Information and HIPAA Form........................................ 49

Table C2. Participant Demographic Questionnaire.....................................53

Table C3. Participant Post-Race Questionnaire .........................................54

Table D1. Each participants' class status and preseason/postseason ferritin levels..............55

Table D2. Correlations between ferritin levels, measures of performance, recovery, and sleep..55

Table D3. Correlations between ferritin levels, measures of performance, recovery, and sleep

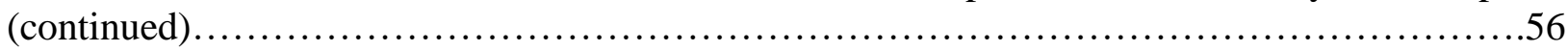




\section{LIST OF FIGURES}

Figure D1. Mile race times over the indoor track and field season..........................57

Figure D2. 3000 meter race times over the indoor track and field season....................57

Figure D3. Average scores of post-race measures of performance and recovery $\ldots . . . \ldots \ldots \ldots . .58$

Figure D4. Freshman ferritin levels over three time points..............................58

Figure D5. Upperclassman ferritin levels over seven time points ........................58

Figure D6. Average RPE scores over the indoor track and field season.......................59 


\section{INTRODUCTION}

Iron is an essential micronutrient in all living organisms. ${ }^{1}$ It has been used medicinally for centuries going back to ancient times, however, the importance of iron was not determined until 1932 when research demonstrated inorganic iron was needed for hemoglobin production. ${ }^{2}$ Iron is recognized in nearly 200 biological processes in the human body including oxygen transport, DNA synthesis, energy metabolism, and hemoglobin production. ${ }^{1,3,4}$ The ability to transition between ferrous and ferric forms allows iron to uptake and offload oxygen. ${ }^{1}$ Iron can be extremely toxic when free-floating in the body due to its oxidative properties. The major benefits and risks demonstrates the need for strict regulation of the micronutrient in the human body. ${ }^{1,4,5}$ The body does not have any active mechanism for iron excretion, thus iron loss is attributed primarily to blood loss. ${ }^{6}$ The average person loses $1-2 \mathrm{mg}$ of iron per day. ${ }^{7,8}$ Iron uptake becomes increasingly important to maintain iron balance. Without sufficient iron intake and absorption to counteract iron loss, the body becomes iron deficient. ${ }^{1,3}$

Iron deficiency is the most common nutritional deficit worldwide affecting over one billion people ${ }^{9}$ with female endurance runners incident rates ranging from $20-50 \%{ }^{3,10}$ Typically, iron deficiency presents with fatigue, delayed recovery, lethargy, nausea, and decreased performance. ${ }^{9,10}$ A continuum exists from iron repletion to iron deficiency and in more severe cases, iron deficiency anemia. ${ }^{3,11-13}$ Based on stability against acute changes, ${ }^{1,2}$ iron status is evaluated using a protein, serum ferritin. Ferritin is strictly regulated by iron. Iron deficiency anemia occurs when hemoglobin levels are low in addition to low serum ferritin levels. ${ }^{1-3,10}$ Since anemia may be caused by different factors, serum ferritin is used to determine if the likely cause is from low iron levels leading to a decreased ability to produce hemoglobin. ${ }^{3}$ Iron is necessary for hemoglobin synthesis as it is needed in the four subunits of hemoglobin. 
In recent years, the importance of hemoglobin as an oxygen carrying mechanism has been demonstrated. However, the largely complex physiological effects of iron deficiency and its causes are, at best, moderately understood. ${ }^{10}$

The longstanding association between iron and performance is well documented..$^{3,6,10,12,14,15}$ Until more recently, performance inhibition believed to be stemming from iron deficiency was often rationalized as a decrease in oxygen carrying capacity. However, in many cases, hemoglobin levels are unaffected beyond the acceptable ranges. In recent years, the focus has shifted to tissue oxidation as an explanation for decreased performance. In elite endurance sports, the idea that increased red blood cells increase the oxygen carrying capacity led to the practice of blood doping. ${ }^{16}$ As consistently shown in the literature, iron is strictly regulated by the body. Hepcidin is the key regulator of iron, being released to prevent further absorption of iron. ${ }^{12,17}$ An increased hepcidin response occurs during exercise when iron utilization may be increased, thus inhibiting uptake of iron. ${ }^{12,17}$ This response can last for several hours creating an extended period of time without adequate iron absorption taking place. ${ }^{12,17 u}$

The effects of iron deficiency on performance in distance runners have been reported in the literature. The importance of iron with direct implications on endurance athletes has led to a belief that ferritin levels are a direct indicator of performance. As ferritin levels change over time, does this change have an effect on rate of perceived exertion, nutrition, hydration status and sleep? Furthermore, will a longitudinal study constitute more information than short-term studies on ferritin levels? The stability of ferritin in the diagnosis of iron deficiency demonstrates the need for more long-term longitudinal studies to be performed with female endurance runners. 
Therefore, the purpose of this study was to investigate whether the change in ferritin levels affect measures of performance, measures of recovery, and rate of perceived exertion in female endurance runners.

\section{METHODS}

Design

The study is a descriptive longitudinal design to determine if a relationship exists between ferritin levels and measures of performance and whether returning athletes' change in ferritin levels over time are different compared to first year/freshman athletes' change in ferritin levels in collegiate distance runners. Distance runners who are members of the university women's Cross Country/Track \& Field team served as participants in the study. Measures observed included serum ferritin, demographic data, and self-reported post-race questionnaire data. Ferritin levels were determined by using existing data collected during regularly scheduled testing between each season (cross country, indoor track and outdoor track), which is approximately every three months. Testing was conducted in February, May, August, and November of each year.

Participants

Ten distance and cross country runners on the university's Cross Country/Track \& Field team were recruited as participants in this study. Participants were $20.0 \pm 1.4$ years old. Inclusion criteria included any active distance runner on the university women's Cross Country/Track \& Field team who were included on the roster and have a sport physical on file. Exclusion criteria included any injury resulting in greater than six months from training in the previous two years. This study was approved by the institution's Office of Research Compliance and Integrity.

Instruments 
Self-reported questionnaire. A demographic questionnaire was administered prior to participation in the study to identify exclusion criteria that may obscure results. The demographic questionnaire contained 11 separate questions related to the participants' academic year, any previous diagnosis of iron deficiency, iron supplementation, severe injury or illness, and menstrual periods. Question types included forced choice, fill-in-the-blank, and check-box. A post-race questionnaire consisting of 11 questions was administered to each of the participants following each participant's respective event during the 2019 indoor track and field season to measure rate of perceived exertion (RPE), hours of sleep the prior night and prior three nights, hydration status, and dietary status. Question types include forced choice and fill-in-the-blank. Seven of the questions related to measures of performance and recovery are on a 6-point Likerttype scale requiring a forced choice response. Questions for the post-race questionnaire were adapted from the Borg Rate of Perceived Exhaustion scale ${ }^{18}$ and the RESTQ-Sport questionnaire $^{19}$. The demographic and post-race questionnaires were reviewed by two certified athletic trainers and a psychometric expert for clarity and readability.

Abbott Architect $i 2000$ (Abbott Laboratories, Abbott Park, IL). All blood sample results were obtained from medical charts as part of regular blood testing completed four times a year during the competitive seasons. Blood samples were obtained in February, May, August, and November of each year by an independent laboratory, which processed the blood samples for ferritin on the Abbott Architect $i 2000$ via immunoassay analyzation. Laboratory equipment evaluating serum ferritin levels are found to be reliable, although variation exists between equipment. ${ }^{20}$

Beckman Coulter DxH (Beckman Coulter, Miami, FL). All blood sample results were obtained from medical charts as part of regular blood testing completed four times a year during 
the competitive seasons. Blood samples were obtained in February, May, August, and November of each year by an independent laboratory, which processed the blood samples for hemoglobin and hematocrit on the Beckman Coulter DxH. The process to analyze hemoglobin is via proprietary hemoglobin analysis. Hematocrit is measured using a calculated measure. Reliability and validity have not been determined on a $+/$ - basis.

Procedures

After West Virginia University Institutional Review Board approval, distance runners on the university women's Cross Country/Track \& Field team on the roster for cross country were contacted via email and/or in-person to participate in this study. Information regarding the study was included in the informed consent (Table C1) form provided to the participant during the meeting. Once the prospective participant agreed to participate in the study and the inform consent form was signed and dated by the prospective participant and the co-investigator, the participant was provided the demographic questionnaire (Table C2) to identify qualifications meeting inclusion and exclusion criteria. For the participants who met the inclusion criteria, each received the post-race questionnaire (Table C3) after each event competed during the 2019 indoor track and field season. Each participant was expected to compete in six to seven events during the season. Ferritin levels from existing data were obtained prior to and after the 2019 indoor track and field season. Freshmen were expected to have three time-points observing ferritin levels with roughly three months between each time point. Upperclassmen were expected to have at least seven time-points observing ferritin levels with roughly three months between each time point. The most recent seven time-points were used and were obtained over a two-year period. The final blood testing for the 2018-2019 academic year would occur in May after the conclusion of this study, thus limiting the ferritin, hemoglobin, and hematocrit blood tests to 
three and seven for freshmen and upperclassmen, respectively. Ferritin levels were regularly evaluated via blood samples obtained for all distance runners on the active roster the institution's Cross Country/Track \& Field team.

Data Analysis

Data was collected to evaluate if there is a difference between rate of increase or decrease in serum ferritin levels of freshman and upperclassman participants. The change in serum ferritin levels for freshman participants was plotted over the three time-points between the beginning of the 2018 academic year in August, November and February 2019. The change in serum ferritin levels for returners was plotted over the seven time-points collected at the beginning of the 2017 academic year through those collected in February 2019.

Data was collected to evaluate if ferritin levels have any relationship to measures of performance and recovery. A preseason ferritin measure obtained in November 2018 was analyzed compared with a postseason ferritin measure obtained in February 2019. Measures of performance included stress, injury, illness, and sleep and was compared with ferritin levels to determine presence of a significant correlation. Measures of recovery included questions related to rate of perceived exertion (RPE), nutrition, hydration, stress, and sleep from the previous night and the previous three nights.

Statistical Analysis

Descriptive statistics for RPE and sleep included means and standard deviations. Questions related to nutrition, hydration, and stress was scored on a 6-point forced choice Likerttype scale. Each answer was assigned according to the following scale: Strongly Disagree (-3), Disagree (-2), Slightly Disagree (-1), Slightly Agree (1), Agree (2), and Strongly Agree (3). This was used to determine if nutrition, hydration status, and stress had a positive or negative 
relationship with ferritin levels. The aforementioned data in addition to hours of sleep from the previous night and hours of sleep from the previous three nights was tested against ferritin for the presence of any statistically significant correlation.

A $1 \times 2$ repeated measures analysis of variance (ANOVA) was performed to observe if a difference exists between preseason and postseason ferritin levels during the two time points. A $1 \times 6$ repeated measures ANOVA for rate of perceived exertion to determine if there was any change in rate of perceived exertion over the course of the 2019 indoor track and field season was unable to be performed due to missing values since not all participants competed in at least one race each meet. A p-value of $\mathrm{P}=0.05$ was used for all analyses to determine significance with a $\mathrm{P}=0.01$ being noted when present. Statistical tests were run using IBM-SPSS Version 25.0 for Windows (IBM-SPSS, Armonk, NY).

\section{RESULTS}

Demographic Data

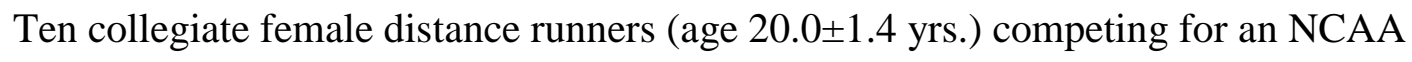
Division I Mid-Atlantic university during the 2019 indoor track and field season participated in this study. Three (30\%) participants were competing in their first collegiate indoor track and field season. Seven (70\%) participants were upperclassmen having competed in at least one prior collegiate indoor track and field season. Seven (70\%) participants identified as White. Two (20\%) participants identified as Mixed. One (10\%) participant identified as Black/African American. Eight (80\%) participants supplemented with ferrous sulfate, one (10\%) supplemented with ferrous gluconate, and one (10\%) participant did not supplement iron. Four (40\%) participants had 12 menstrual periods in the previous 12 months. Four participants had seven to eleven menstrual periods in the previous 12 months. Two participants were amenorrhoeic. The 
most common race competed by the participants was the mile $(n=15)$ with the $3000 \mathrm{~m}$ was the second-most common race competed by the participants $(n=14)$. Since not all participants competed in each distance race, race times were reported for only subjects $2,3,5,9,10$ for the 1 mile race. (Figure D1) In addition, race times were reported for subjects 1, 2, 3, 7, and 9 for the 3000 meter race. (Figure D2) Post-race questionnaire data scores were as follows: felt hydrated (1.56 \pm 1.51$)$, felt fueled (1.87 \pm 0.93$)$, felt stress-free $(0.28 \pm 1.47)$, felt well-rested $(1.37 \pm 1.51)$, did not feel fatigued $(0.81 \pm 1.72)$, felt performed well $(1.09 \pm 1.83)$, did not feel ill or injured $(2.44 \pm 1.18)$ with a minimum and maximum score of -3 and 3 , respectively. (Figure D3) The average total score was $9.43 \pm 5.54$ with a possible minimum and maximum score of -18 and 18 , respectively. Participants received an average of $8.15 \pm 0.83$ hours of sleep the night prior to the respective race and received an average of $8.20 \pm 0.68$ hours of sleep averaged over the prior three nights to the respective race. The mean RPE score was $17.17 \pm 1.85$.

Ferritin Levels Over Time

Two of the three freshman participants experienced decreased levels of ferritin for three time points in six months, while one experienced increased ferritin levels (Figure D4). Four of the upperclassmen experienced decreased ferritin levels for seven time points in eighteen months while three experienced increased ferritin levels (Figure D5).

Preseason/Postseason Ferritin Levels

The mean preseason ferritin level was $50.33 \pm 17.94$ with one case being excluded as an outlier. The mean postseason ferritin level was $46.33 \pm 17.75$ with one case being excluded as an outlier. The outlier was removed as the participant received an iron infusion treatment artificially elevating ferritin levels. There was no significance in average preseason ferritin levels and average postseason ferritin levels $\mathrm{F}_{1,8}=1.767, \mathrm{p}=0.220$. Refer to Table D1 for additional results. 


\section{Partial Correlation Results}

Ferritin levels and performance: Measures of felt hydrated, felt fueled, and felt performed well had low correlations and did not have a significant relationship with ferritin difference. Additionally, as hemoglobin concentration decreased, ferritin concentration increased $(r=-0.64$, $\mathrm{p}<0.001)$ with a moderate effect $\left(\mathrm{r}^{2}=0.41\right)$. Refer to Table D2 and Table D3 for additional results.

Ferritin levels and recovery: A partial correlation analysis indicated a significant moderate relationship between ferritin levels and feeling ill or injured $(r=0.42, p=0.002)$.

Ferritin levels and sleep: A partial correlation analysis indicated no significant relationship with hours of sleep the previous night and ferritin difference $(r=0.09, p=0.51)$, however a significant moderate relationship existed between average hours of sleep over the previous three nights and ferritin difference $(\mathrm{r}=0.315, \mathrm{p}=.021)$.

Ferritin levels and RPE: A 1 x 6 repeated measures ANOVA was unable to be performed due to incomplete data. Not all participants completed at least one race in each meet. A partial correlation indicated a significant moderate relationship between ferritin difference and rate of perceived exertion $(r=0.407, \mathrm{p}=0.002)$. Average RPE scores were graphed over time (Figure D6) and were shown to increase over the course of the season.

\section{DISCUSSION}

The purpose of the study was to observe ferritin levels over time and to determine if a relationship existed between ferritin levels and measures of performance, recovery, and sleep prior to and three days before competition using collegiate female distance runners during the indoor track and field season at one institution. The results of this analysis showed there were significant moderate correlations between ferritin difference and feeling ill or injured, ferritin difference and average hours of sleep the previous three nights before competition, and ferritin 
difference and rate of perceived exertion. In addition, two of the three freshman participants experienced decreased levels of ferritin for the three time points over six months, while one experienced increased ferritin levels. Four of the upperclassmen experienced decreased ferritin levels over seven time points within eighteen months while three experienced increased ferritin levels.

There were four experimental hypotheses in this study; two regarding change in ferritin levels based on years of participation in college and two regarding ferritin difference on various measures of performance, recovery, rate of perceived exertion, and sleep. The hypothesis that freshman distance runners' ferritin levels will decrease or remain constant over the course of the first year was supported by the results. For upperclassman distance runners, the hypothesis that ferritin levels will remain constant or increase was not supported by the results. However, when accounting for training period, comparing ferritin levels at the same point in the previous year, five of seven upperclassman participants experienced increased ferritin levels. Because participation from the freshman and upperclassman groups were three and seven, respectively, a larger sample size would better provide support for hypotheses $1 \mathrm{a}$ and $1 \mathrm{~b}$. The hypothesis that as ferritin levels increase or remain constant, RPE will decrease and as ferritin levels decrease, RPE will increase was not supported by the results. A significant moderate positive correlation between ferritin levels and RPE was observed. Additionally, the hypothesis that as ferritin levels increase or remain constant, physical measures will increase and as ferritin levels decrease, physical measure will decrease was partially supported in this study. A partial correlation was found to exist between ferritin levels and self-reported scores of feeling ill or injured and average hours of sleep the three previous nights. No significant partial correlations were found to exist between ferritin difference and feeling hydrated, feeling fueled, feeling stress-free, feeling well- 
rested, feeling fatigued, feeling performed well, and hours of sleep the previous night. All had low correlations with ferritin difference.

\section{Ferritin Levels Over Time}

Over time, ferritin levels will adjust due to many variables including iron intake and utilization, iron loss, training load and volume, and some certain conditions related to iron malabsorption or blood loss..$^{3,6,7,21}$ This is typically the result of blood loss through the gastrointestinal tract or through menses. ${ }^{22,23}$ For an endurance runner, gastrointestinal distress leading to occult blood loss is not an uncommon occurrence. ${ }^{23}$ In the female endurance runner population, menses become increasingly important when considering blood loss. ${ }^{22}$ In this study, 8/10 participants had a menstrual cycle with two participants being amenorrhoeic.

As a female distance runner increases training volume, such as going from competing on a high school team to a collegiate team, ferritin levels are likely negatively affected. To resolve the issue of low iron within the body, supplementation often occurs. Among the seven upperclassman participants, four experienced a net decrease in ferritin levels from time point one to time point seven in the eighteen-month period while three experienced a net increase. When observing ferritin levels, comparing the same competition season from year-to-year is likely a better indicator of whether a participant was adversely affected by training and competition. When observing upperclassman ferritin levels from the post-2018 indoor track season levels to the post-2019 indoor track season levels, five participants' levels increased, while only two decreased supporting the notion that after adjusting to an increase in training load and volume, ferritin levels are maintained or increased.

In distance runners who are iron deficient or iron deficient anemic, supplementation has been shown to improve performance and endurance capacity in both men and women. In this 
study, all but one distance runner was on iron supplementation. Periodic supplementation in runners who are iron sufficient may prevent future incidence of iron deficiency, but there is little support that consistent supplementation in runners who are iron sufficient experience improved performance. ${ }^{24,25}$ Recommendations for iron testing is to obtain bloodwork once or twice per year to determine iron status and begin, maintain, adjust, or discontinue any iron intervention. ${ }^{24}$ To resolve the issue of low iron within the body, supplementation often occurs. In athletes who had ferritin levels within the reference range, use of oral supplementation is supported, but iron infusion is questionable.

For intravenous iron supplementation, an iron infusion is performed in place of oral supplementation. Because rapid changes in iron levels in the body can be harmful to the organs, the procedure is typically staged over multiple treatment sessions each lasting several hours. Woods, et al. ${ }^{15}$ observed recovery measures such as mood disturbance and perceived fatigue when supplemented via intravenous injection. Ferric-carboxymaltose injections were chosen as the intervention. Perceived fatigue and mood disturbances decreased over four weeks. With intravenous supplementation, performance is slightly increased for an endurance distance event. ${ }^{26}$ In a sprint or repeat-sprint events, performance does not appear to increase. While there is a positive effect on the perception of recovery, intravenous supplementation is not shown to increase overall performance. Schröder, et al. ${ }^{27}$ found that the high doses of intravenous iron supplementation are associated with relatively few short-term adverse effects. In selecting an intravenous or intramuscular iron supplement, there is not as wide of a selection compared to an oral iron supplement. ${ }^{26}$

One participant had an iron infusion prior to collegiate participation which elevated her ferritin levels significantly. Her levels were elevated higher than the ferritin upper reference 
value of $200 \mathrm{ng} / \mathrm{dL}$. It is expected that elevated ferritin levels will decrease to within a normal range if there are no associated conditions. In this case, ferritin levels were returned to the normal range (20-200 ng/dL) at the end of the three observed time points. When levels are elevated, there is concern for hemochromatosis. The subject's first ferritin level was recorded at $383 \mathrm{ng} / \mathrm{dL}$ in February 2018. Six months later her levels declined to $269 \mathrm{ng} / \mathrm{dL}$ and returning to the acceptable range three months later at $197 \mathrm{ng} / \mathrm{dL}$. The subject reported no adverse reactions to the elevated levels or any perceived affect on performance. The athlete also did not report any injuries requiring more than a week off from training.

Increased training volume and load is linked with decreased iron status. ${ }^{28}$ As training load increases and more iron is utilized in the body, a net decrease in iron stores occurs. ${ }^{28}$ When observing preseason and postseason ferritin levels, the levels are expected to decrease unless the training volume is relatively unchanged or decreases. Collegiate distance runners participate in sport year-round. Their training load may fluctuate to a degree, however, to maintain cardiovascular fitness, distance runners often maintain a certain level of training throughout the year unless ill or injured. Observing ferritin levels at a single season preseason time point and a postseason time point does not provide an accurate picture since preceding training load and volume have an impact on ferritin levels.

Ferritin Levels and Performance

Performance is often observed through a standardized treadmill test such as the $\mathrm{VO}_{2}$ max test. Iron is an important factor in various aerobic pathways and a decrease in elite female distance runners' performance in the presence of iron deficiency may be better explained by impaired tissue oxidation. Field performance such as race times are difficult to obtain due to the lack of standardization. Often, collegiate distance runners do not compete in the same event 
week-to-week and they do not always compete in every meet. This poses a greater challenge to accurately determine changes in performance. Means to indirectly observe indicators of performance exist through self-reported measures, however, critical evaluation of these measures is limited.

In this study, performance could not be evaluated using race times as not all participants competed in all the meets and each participant did not always compete in the same distance. From the data collected, only one participant competed in each of the six meets. Therefore, a self-report post-race questionnaire was administered after the distance runner competed in an event. This questionnaire inquired about RPE, nutrition status, hydration status, stress and being ill or injured.

A correlation between ferritin difference and feeling ill or injured is consistent with the idea that iron status is associated with signs and symptoms such as lethargy, dyspnea, dizziness, lightheadedness, and delayed recovery. ${ }^{7,10}$ No correlation was found between ferritin difference and self-reported measures of felt hydrated, felt fueled, felt stress-free, felt well-rested, did not feel fatigued, and felt performed well. Recovery is used to determine readiness of an athlete to perform in the next training session. ${ }^{29}$ Under-recovered athletes experience decreased performance. Because iron is tightly regulated in the body to prevent excessive oxidation, iron stores take weeks to replenish from a deficiency. Athletes who are in a negative iron balance and are under-recovered between training sessions are likely to enter a cyclical nature of decreased iron stores and recovery unless training volume or load is adjusted. ${ }^{3,7}$ As there is very little information in the literature on performance for any athletes ${ }^{14}$ or endurance runners and performance, except in relation to iron supplementation, ${ }^{6,712,15}$ it is difficult to draw conclusions 
about ferritin levels and performance. Thus, warranting the need for additional studies to be performed on ferritin levels and the effect on performance.

Ferritin Levels and Nutrition

Nutritional consideration is another major factor affecting performance. Nutrition has long been identified as a factor of performance. Proper nutrition is important for development and maturation in adolescents and to achieve high athletic performance. Athletes require additional energy to meet the demands of sport. Intake must meet expenditure to maintain energy balance. ${ }^{30}$ With a negative energy balance, development and performance may become inhibited. Female cross country runners or endurance athletes are commonly seen as a high-risk group for eating disorders. Physical appearance and body image can exacerbate the issue of inadequate nutrient intake. Eating disorders are pervasive in collegiate female distance runners. In 2016, $27.2 \%$ of collegiate female distance runners reported suffering from an eating disorder either currently or in the past compared with $6.3 \%$ of collegiate male distance runners. ${ }^{31}$ Nearly $70 \%$ of female respondents reported their weight affected the way they felt about themselves. ${ }^{31}$ Despite eating disorders being prevalent in collegiate female distance runners, nearly all female collegiate athletes are found to have inadequate intake for their energy needs. ${ }^{30}$ Inadequate intake results in lower levels of metabolic functions and decreased micronutrients needed for the body to maintain homeostasis. ${ }^{32}$ As intake decreases, aerobic performance is found to decrease as metabolic pathways become impaired. ${ }^{32}$ In this study, there was a low correlation with ferritin levels and felt fueled. It was surmised that nutrition status did not seem to have an effect with ferritin levels. 
Ferritin Levels and Hydration

Hydration is yet another factor often considered to affect and be a determinant of performance. Being well-hydrated prior to exercise and fluid replacement during exercise is important to preventing decreased performance. The American College of Sports Medicine published an updated position stand in 2007 on dehydration in athletes and defined dehydration as $2 \%$ body weight loss, stating that any loss greater than $2 \%$ degrades aerobic performance in warm to hot environments. ${ }^{33}$ The goal for endurance athletes is to prevent a $2 \%$ loss from occurring during exercise. Hypohydration of $2.6 \%$ to $5.6 \%$ of body weight prior to activity impairs high intensity activity lasting 5 to 30 minutes. ${ }^{34}$ Oxygen consumption is further decreased at a rate of $2.9 \%$ for every percent body weight lost beyond $3.1 \% .{ }^{34}$ Recently, five laboratory studies simulating real-world conditions found no impairment to endurance performance from exercise-induced body weight loss. ${ }^{34}$ These studies challenged the findings of those used to establish the $2 \%$ body weight loss during exercise, suggesting the research protocols did not simulate real-world conditions.

New recommendations suggest establishing a well-hydrated state prior to exercise, but only consuming fluids ad libitum during exercise. ${ }^{34}$ Consumption of fluids during exercise has been shown to cause gastrointestinal distress, thereby decreasing performance. This study utilized self-reported scores of how well the athlete felt hydrated during the race. In this study, as with nutrition status, there was no significant relationship found between ferritin difference and feeling hydrated, nor was there a significant relationship found between feeling hydrating and feeling performed well. 


\section{Ferritin Levels and Sleep}

Iron deficiency is associated with decreased hours and quality of sleep. Sleep is

commonly considered to determine an athlete's level of recovery between training. ${ }^{35}$

Psychometric measurements of recovery have found the prior three days may be more significant than the day prior. Interestingly, no correlation was found to exist between ferritin difference and hours of sleep prior to competition in this study, however the average hours of sleep from the three prior nights are more closely associated with ferritin difference. Speed and endurance are both inhibited when two or more hours of sleep is lost. ${ }^{36}$ Another result of sleep loss is the increase in injury and illness risk. ${ }^{35}$ Athletes receiving less than eight hours of sleep per night are at an almost doubled chance of suffering a significant injury.

Besides direct effects on athletic performance, sleep can also create weight issues, mood disturbances, and increased stress. ${ }^{35,37}$ Research observing collegiate female distance runners and sleep is limited. In a study observing ultramarathon runners, sleep disorders were found in nearly $40 \%$ of females. ${ }^{36}$ Most ultramarathon runners reported receiving six to eight hours of sleep during weekdays and seven to nine hours on weekends and holidays. ${ }^{36}$ Research observing aerobic performance impacted by circadian rhythm revealed mixed results of exercise occurring at different times throughout the day. ${ }^{37}$ Interestingly, anaerobic performance was found to not be impacted by sleep deprivation, while aerobic performance was affected and multiple studies have found similar findings. ${ }^{37} \mathrm{Female}$ endurance runners should continue to maintain an average of eight hours of sleep during the three previous nights.

Ferritin Levels and Rate of Perceived Exertion

A common measure to evaluate effort and performance is rate of perceived exertion (RPE). In female distance runners, the validity of RPE as an indicator of oxygen carrying 
capacity has been challenged. Iron supplementation has been found to have no significant effect on RPE. Ferritin difference was found to be positively correlated with RPE in this study. RPE is often used to predict $\mathrm{VO}_{2}$ max and these findings are consistent with newer research suggesting $\mathrm{RPE}$ and $\mathrm{VO}_{2}$ max are both invalid indicators of performance in endurance athletes, particularly competitive distance runners. ${ }^{15,38-41} \mathrm{~A}$ considerable factor affecting results determining reliability and validity of Borg's RPE scale is the protocol used.$^{38}$ No study was found to determine validity of reliability of RPE in collegiate or elite distance runners during competition. In a systematic review, RPE was not found to be a valid indicator of $\mathrm{VO}_{2}$ max in elite distance runners and suggested more sensitive testing is required for highly trained athletes who have developed adaptations from aerobic performance. ${ }^{38}$ Additionally, $\mathrm{VO}_{2}$ max as a predictor of performance has been questioned. In a study observing race times, $\mathrm{VO}_{2}$ max was not a predictor of race performance in a 5000 meter race. ${ }^{39}$

In this study, the data was controlled for the total meets in which each participant competed since not all participants competed in every meet. The average RPE increased over time over each of the six meets from 16.33 during the first meet to 17.80 during the last meet. One explanation for the increase over time is the level of competition at each meet. As the season progressed and finished with the conference championship, the level of competition may increase over time and in distance races where field pace can vary, RPE may be affected accordingly.

Based on the self-report information obtained, there was a moderate relationship between ferritin levels and perceived exertion. As the season progressed, average RPE scores increased over the course of the season. However, more research is still needed observing race performance with means developed to evaluate real-time racing events rather than laboratory 
studies with treadmill or cycling progressions. Further, research is needed observing race performance rather than laboratory studies with treadmill or cycling progressions to determine the usefulness of $\mathrm{VO}_{2}$ max and RPE as measures of performance in female endurance athletes. Clinical Importance

This was the first study to provide a comprehensive investigation into ferritin levels and measures of performance, recovery, RPE, and sleep in collegiate female distance runners. As this population is at-risk for developing iron deficiency, information on iron status and the associated effects is increasingly important for health and performance. The negative implications of iron deficiency can impact both short and long-term health. Clinicians may benefit from the results of this study to consider iron deficiency and ferritin levels in female endurance athletes. Results were consistent with the hypothesis that female endurance athletes who are changing training load and volume, such as the start of freshman year, may see reduced levels of ferritin. With upperclassmen female endurance athletes who are likely maintaining a more consistent training load and volume compared to freshman cohorts, ferritin levels are likely to remain stable. This study was unable to account for training volume and load due to the short six-week data collection period and highly variable factors contributing to training volume (inconsistent schedule, lack of consistent measurements for workouts, etc.). Within a competitive season, an overall decline in ferritin levels among participants was evident, however the sample size was small $(\mathrm{n}=10)$ and may not translate to similar results at other institutions. Ideally, training loads and volumes would remain consistent over time and between participants, however in the context of varsity collegiate athletes, this is difficult to control.

From this study several significant correlations, all with moderate effects, were noted. Female distance runners who experience a decrease in ferritin correlated with increased levels of 
feeling ill or injured. This study also supported amount of sleep over three previous nights rather than the amount of sleep from the night prior. The implications that sleep and recovery have on productivity and physical performance is consistently shown, especially for the three nights prior to competition. When observing ferritin difference and RPE, results from this study was contradictory to what is expected if RPE is a direct measure of performance and if change in ferritin levels indicate a change in performance. However, the validity of RPE has been challenged more recently when the population is endurance athletes. Observing RPE may still hold significance in non-endurance recreational athletes, but when observing female distance runners, results did not support the hypothesis.

If using ferritin levels to determine iron status, other hematological factors need to be observed. Athletes who are supplementing iron should be followed to ensure appropriate levels are maintained and that one remains within the normal range, especially if an infusion is performed. Further, ferritin levels should not be the only consideration over the season. As ferritin level are observed at different time points, other factors should be considered such as RPE, sleep, recovery and performance. A self-report questionnaire similar to what was used in this study should also be included following each race competed to observe the other factors in relation to ferritin levels and performance.

\section{Limitations}

The data obtained in this study is preliminary and additional investigation is warranted. Several limitations were noted which provide a basis for future research to continue examination of ferritin levels with competitive female distance runners. The sample size for this study was ten which makes the data less generalizable to the population. Participants were from a single institution which may make extrapolating the results to other institutions more difficult. The 
institution at which the data collection took place did not have varsity men's cross country/track and field program. Comparison to collegiate male distance runners would provide a better picture if ferritin levels correlate as significantly with female distance runners. The study relied on selfreported data which requires the participants to interpret the questions in the same way and score consistently. When observing performance, race times were initially considered, however, not all participants compete in the same race nor race at consistent intervals over time making it difficult to observe over the six-week data collection period. Controlling for this would require additional exercise testing which coaches or participants may not be willing to perform. Many previous studies have used laboratory protocols, but newer research is using real-world situations such as marathons, or laboratory studies simulating real-world situations to observe performance providing legitimacy to using race times as a means of performance, although making it difficult to control many variables.

Controlling for ferritin levels is extremely difficult. Many factors affect iron status not related to training such as dietary intake, supplementation, absorption, and blood loss. This study did not control for supplementation and supplementation groups were unequal ( $\mathrm{n}=9$ supplemented; $\mathrm{n}=1$ did not supplement). Iron status is not determined from a single blood test, but rather a panel of biomarkers. Observing ferritin alone and making various assumptions of the effect iron status has on the body does not allow a cause-effect relationship to be established. To mitigate many of these limitations, a demographic questionnaire was completed by each participant to determine possible confounding variables, which would skew the results.

\section{CONCLUSION}

Ferritin can be a valuable tool in determining iron status in the body and is associated with several measures of recovery. Regular ferritin testing with other hematological biomarkers 
provide a comprehensive analysis of factors that influence levels of aerobic capacity. Difference in iron stores have a significant relationship with measures of recovery. Two of the three freshman participants experienced decreased levels of ferritin for the three time points over six months, while one experienced increased ferritin levels. Four of the upperclassmen experienced decreased ferritin levels over seven time points within eighteen months while three experienced increased ferritin levels. Significant moderate correlations were noted between ferritin difference and feeling ill or injured, average hours of sleep the previous three nights before competition, and rate of perceived exertion. This can be used to determine levels of recovery in collegiate female distance runners. 


\section{REFERENCES}

1. Duck KA, Connor JR. Iron uptake and transport across physiological barriers. Biometals. 2016;29:573-579.

2. Abbaspour N, Hurrell R, Kelishadi R. Review on iron and its importance for human health. J Res Med Sci. 2014;19(2):164-74.

3. Clénin G, Cordes M, Huber A, et al. Iron deficiency in sports - definition, influence on performance and therapy. Swiss Med Wkly. 2015;145:w14196.

4. Andrews NC, Schmidt PJ. Iron homeostasis. Annu Rev Physiol. 2007;69:69-85.

5. Arosio P. Levi S. Ferritin, iron homeostasis, and oxidative damage. Free Radic Biol Med. 2002;33(4):457-63.

6. Alaunyte I, Stojceska V, Plunkett A. Iron and the female athlete: a review of dietary treatment methods for improving iron status and exercise performance. J Int Soc Sports Nutr. 2015;12:38.

7. Hinton PS. Iron and the endurance athlete. Appl Physiol Nutr Metab. 2014;39(9):1012-8.

8. Daher R, Manceau H, Karim Z. Iron metabolism and the role of the iron-regulating hormone hepcidin in health and disease. Presse Med. 2017;12(2):e272-e278.

9. DeMaeyer E, Adiels-Tiegman M. The prevalence of anemia in the world. World Health Stat Q. 1985;38:302-16.

10. Brumitt J, Mcintosh L, Rutt R. Comprehensive Sports Medicine Treatment of an Athlete Who Runs Cross-Country and is Iron Deficient. N Am J Sports Phys Ther. 2009;4(1):1320 .

11. Auerback M, Adamson JW. How we diagnose and treat iron deficiency anemia. Am J Hematol. 2016;91(1):31-8.

12. Coates A, Mountjoy M, Burr J. Incidence of Iron Deficiency and Iron Deficient Anemia in Elite Runners and Triathletes. Clin J Sport Med. 2017;27(5):493-498.

13. Pratt JJ, Khan KS. Non-anaemic iron deficiency - a disease looking for recognition of diagnosis: a systematic review. Eur J Haematol. 2016;96(6):618-28.

14. Dellavalle DM, Haas JD. Iron supplementation improves energetic efficiency in irondepleted female rowers. Med Sci Sports Exerc. 2014;46(6):1204-15. 
15. Woods A, Garvican-lewis LA, Saunders PU, et al. Four weeks of IV iron supplementation reduces perceived fatigue and mood disturbance in distance runners. PLoS ONE. 2014;9(9):e108042.

16. Remacha AF, Ordoñez J, Barcelo MJ, Garcia-die F, Arza B, Estruch A. Evaluation of erythropoietin in endurance runners. Haematologica. 1994;79(4):350-2.

17. Frazer DM, Anderson GJ. Intestinal iron absorption and its regulation. Am J Physiol Gastrointest Liver Physiol. 2005;289(4):G631-5.

18. Chen MJ, Fan X, Moe ST. Criterion-related validity of the Borg ratings of perceived exertion scale in healthy individuals: a meta-analysis. J Sports Sci. 2002;20(11):873-99.

19. Filho E, Di fronso S, Forzini F, et al. Athletic performance and recovery-stress factors in cycling: An ever changing balance. Eur J Sport Sci. 2015;15(8):671-80.

20. Zhang X, Lu Y, Ma L, Peng Q, Qin X, Li S. A comparison study between two analyzers for determining serum ferritin. Clin Lab. 2015;61(1-2):169-74.

21. Clark S. Iron Deficiency Anemia. Nutr Clin Pract. 2008;23(2):128-141.

22. Bruinvels G, Burden R, Brown N, Richards T, Pedlar C. The Prevalence and Impact of Heavy Menstrual Bleeding (Menorrhagia) in Elite and Non-Elite Athletes. PLoS ONE. 2016;11(2):e0149881.

23. Robertson JD, Maughan RJ, Davidson RJ. Faecal blood loss in response to exercise. $\mathrm{Br}$ Med J (Clin Res Ed). 1987;295(6593):303-5.

24. Zourdos MC, Sanchez-Gonzales MA, Mahoney SE. A brief review: the implications of iron supplementation for marathon runners on health and performance. J Strength Cond Res. 2015;29(2):559-65.

25. Rubeor A, Goojha C, Manning J, White J. Does Iron Supplementation Improve Performance in Iron-Deficient Nonanemic Athletes?. Sports Health. 2018(10)5:400-405.

26. Klingshirn LA, Pate RR, Bourque SP, Davis JM, Sargent RG. Effect of iron supplementation on endurance capacity in iron-depleted female runners. Med Sci Sports Exerc. 1992;24(7):819-24.

27. Schröder O, Mickisch O, Seidler U, et al. Intravenous iron sucrose versus oral iron supplementation for the treatment of iron deficiency anemia in patients with inflammatory bowel disease - a randomized, controlled, open-label, multicenter study. Am J Gastroenterol. 2005;100(11):2503-9. 
28. Rowland T, Deisroth M, Green G, Kelleher J. The effect of iron therapy on the exercise capacity of nonanemic iron-deficient adolescent runners. Am J Dis Child. 1988;142:165169.

29. Casazza GA, Tovar AP, Richardson CE, Cortez AN, Davis BA. Energy Availability, Macronutrient Intake, and Nutritional Supplementation for Improving Exercise Performance in Endurance Athletes. Curr Sports Med Rep. 2018;17(6):215-223.

30. Shriver LH, Betts NM, Wollenberg G. Dietary intakes and eating habits of college athletes: are female college athletes following the current sports nutrition standards?. $J$ Am Coll Health. 2013;61(1):10-6.

31. Krebs PA, Dennison CR, Kellar L, Lucas J. Gender Differences in Eating Disorder Risk among NCAA Division I Cross Country and Track Student-Athletes. J Sports Med. 2019;2019:5035871.

32. Deldicque L, Francaux M. Recommendations for Healthy Nutrition in Female Endurance Runners: An Update. Front Nutr. 2015;2:17.

33. Sawka MN Burke LM Eichner ER, et al. American College of Sports Medicine position stand. Exercise and fluid replacement. Med Sci Sports Exerc. 2007;39:377-390.

34. Goulet ED. Dehydration and endurance performance in competitive athletes. Nutr Rev. 2012;70 Suppl 2:S132-6.

35. Simpson NS, Gibbs EL, Matheson GO. Optimizing sleep to maximize performance: implications and recommendations for elite athletes. Scand J Med Sci Sports. 2017;27(3):266-274.

36. Martin T, Arnal PJ, Hoffman MD, Millet GY. Sleep habits and strategies of ultramarathon runners. PLoS ONE. 2018;13(5):e0194705.

37. Thun E, Bjorvatn B, Flo E, Harris A, Pallesen S. Sleep, circadian rhythms, and athletic performance. Sleep Med Rev. 2015;23:1-9.

38. Coquart JB, Garcin M, Parfitt G, Tourny-chollet C, Eston RG. Prediction of maximal or peak oxygen uptake from ratings of perceived exertion. Sports Med. 2014;44(5):563-78.

39. Støa EM, Støren Ø, Enoksen E, Ingjer F. Percent utilization of VO2 max at 5-km competition velocity does not determine time performance at $5 \mathrm{~km}$ among elite distance runners. J Strength Cond Res. 2010;24(5):1340-5.

40. Garvican LA, Saunders PU, Cardoso T, et al. Intravenous iron supplementation in distance runners with low or suboptimal ferritin. Med Sci Sports Exerc. 2014;46(2):37685 . 
41. Evans HJ, Parfitt G, Eston RG. The perceptually regulated exercise test is sensitive to increases in maximal oxygen uptake. Eur J Appl Physiol. 2013;113(5):1233-9. 


\section{APPENDICES}




\section{APPENDIX A}

\section{THE PROBLEM}

\section{Research Question}

Iron is a fundamental element critical for many biological processes including oxygen transport, adenosine triphosphate production, electron transport chain, and red blood cell production. Iron is required for nearly 200 biologic functions in the body. ${ }^{3}$ The human body contains roughly 3 to 5 grams of iron depending on factors related to size, sex, and age. ${ }^{8,12}$ Red blood cells, which account for 2.5 to 3 grams of iron in the body, have a lifespan of 120 days. $^{21}$ Hemoglobin, the iron-rich protein found in red blood cells, is responsible for the binding of oxygen, while the red blood cell acts as the vehicle to distribute the oxygen to various organs and other tissues. ${ }^{8,12,21}$ Erythropoiesis occurs in the bone marrow when sufficient iron levels are present. The body does not have a direct mechanism for iron excretion, thus, iron status in the body relies solely on the intake and absorption.

Dietary intake of iron can be from plant-based sources or animal-based sources. ${ }^{6,8,12,21}$ Iron in plant-based foods is non-heme and is found in the ferric form. ${ }^{8}$ Once absorbed in the body via the duodenum, the non-heme iron is converted from the ferric form to the ferrous form. ${ }^{2,8,42}$ The body can also absorb animal-based iron as heme, although this mechanism is unclear. ${ }^{2,8,42}$ Heme is catabolized efficiently and releases iron quickly. ${ }^{8,42}$ The bioavailability of heme iron is $15 \%-35 \%$, whereas non-heme iron has relatively low bioavailability at $2 \%-20 \% .{ }^{2,3}$

Once absorbed, iron is then transported via transferrin. ${ }^{8,12,42}$ Transferrin, produced in the liver, binds two iron atoms and transports to the organs, bone marrow, and iron stores in the body. ${ }^{8,42}$ When not needed, iron is stored via ferritin, a protein that binds to iron preventing it from being utilized elsewhere in the body. ${ }^{8,42}$ Ferritin releases stored iron when signaled. ${ }^{42}$ Sixty- 
five to seventy percent of iron is found in the hemoglobin., ${ }^{2,3}$ Twenty percent is stored via ferritin, primarily in the liver. . ${ }^{2,3}$ The remaining ten to fifteen percent is in myoglobin, bound to transferrin, bound to enzymes, or is free-floating. ${ }^{2,3}$ Iron is lost at a rate of 1-2 mg per day attributed to intestinal epithelial desquamation. ${ }^{2,3,7,8} \mathrm{An}$ additional $1 \mathrm{mg}$ of iron is lost per day from sloughed tissues in menstruating females. ${ }^{2,3}$ No physiologic mechanism exists for the excretion of iron, thus homeostasis of iron in the body is regulated by absorption. ${ }^{2,6,17}$

Because the lifespan of a red blood cell is 120 days, observing iron status through hemoglobin is not particularly accurate. ${ }^{21}$ In an iron deficient state, there is no immediate distinct decline in hemoglobin levels. ${ }^{21,43}$ Free iron, sensitive to various factors including recent consumption, accounts for less than ten percent of iron in the body ${ }^{3}$ and does not provide an accurate depiction of iron status. ${ }^{21,43}$ Observing iron status by ferritin levels are reflective of the body's ability to absorb, transport, and store iron within the body. Ferritin testing is a low cost, minimally invasive test making it the most widely utilized biomarker for determining iron deficiency and iron deficiency anemia. ${ }^{21}$

Sufficient iron in the body regularly stimulates the production of erythropoietin. Conversely, iron deficiency decreases erythropoiesis and as production of erythrocytes decreases, oxygen-carrying capacity is inhibited. The body resorts to less effective pathways of energy production decreasing performance. ${ }^{3}$ Symptoms can often vary and are difficult to directly link to iron deficiency. ${ }^{21}$

$\mathrm{VO}_{2}$ max is often considered the gold standard of aerobic fitness, however, it is not widely considered a predictor of performance in trained endurance runners. While $\mathrm{VO}_{2}$ max can provide insight into the aerobic ability of the athlete, it is not shown to predict field performance outcomes in trained endurance athletes. Some measures of field performance in athletes include 
various distances measured on an ergometer, treadmill, or competitive race. Several studies have determined direct correlation to performance and hemoglobin concentration.

Several studies have aimed to determine decreases in performance attributed to anemia versus that of enzyme impairment. Furthermore, the causation of anemia leading to enzyme impairment may not allow for an accurate comparison. Iron deficiency has been shown to disrupt enzymes during aerobic metabolism. This effect creates an immediate impairment of aerobic performance as well as impacting long-term adaptation to training. Iron status is correlated with performance on all aspects of the training cycle in endurance athletes. ${ }^{14}$

The most common population with iron deficiency in the western world is female athletes, specifically female distance runners. The incidence of iron deficiency in females is due to hormonal changes, blood loss from menses, and dietary deficiencies affecting intake and absorption. Iron deficiency is statistically significant in habitual female runners compared to the comparable inactive female population. ${ }^{44}$ Twenty percent of females in the general public are iron deficient and that increases to fifty percent in female runners. ${ }^{12}$ Elite athletes are another subset of the population recognized to be affected by iron as the intensity and volume of training tends to be greater than most recreational athletes. ${ }^{3,10}$ Elite female endurance athletes are a specific subset of the population that are at a biological disadvantage for the aforementioned reasons. Because fatigue, diminished performance, and prolonged recovery are all considered indicators and predictors of future performance, it is not uncommon for blood testing to be performed when these symptoms are present.

Today, sport performance is a major focus of collegiate athletics and in other realms. Iron deficiency and the negative impact on athletic performance is well studied. ${ }^{3,6,45,46}$ Ferritin has been identified as an important factor in determining iron status as early as the 1930 's. ${ }^{3,43}$ The 
longstanding association of ferritin levels and performance result in a heightened focus on iron supplementation. To date, there are few studies observing if ferritin alone can be predictive of performance in elite female distance runners.

Therefore, the following research questions are asked:

Research Questions

1. Can ferritin levels be used as a predictor for field performance?

2. Is there a specific ferritin level that results in a significant decrease or increase in performance?

Experimental Hypotheses

1a. For freshmen participants, ferritin levels will decrease or stay the same over the three time-points.

1b. For upperclassmen participants, ferritin levels will increase or stay the same over the seven time-points.

2a. As ferritin levels increase or remains constant, RPE will decrease. Conversely, as ferritin levels decrease, RPE will increase.

2b. As ferritin levels increase or remain constant, physical (nutritional, hydration, and sleep) measures will increase. Conversely, as ferritin levels decrease, physical measures will decrease.

Assumptions

1. All participants met the inclusion criteria of the study.

2. The method used to determine ferritin levels was accurate and reliable.

\section{Delimitations}

1. Participants were only from one Division I institution. 
2. Participants were only cross country runners.

3. Participants were only females.

Operational Definitions

1. Aerobic Performance- Exercise requiring oxygen for metabolic systems. ${ }^{14}$

2. Erythropoiesis- the biological process of producing red blood cells. ${ }^{21}$

3. Erythropoietin- a hormone produced in the kidneys responsible for stimulating erythropoiesis. ${ }^{16}$

4. Ferric- Iron with a valence of $3, \mathrm{Fe}^{3}{ }^{3}$

5. Ferrous- Iron with a valence of $2, \mathrm{Fe}^{2+} .3$

6. Ferritin- Intracellular protein that stores iron; primary storage form of iron. ${ }^{6,11,43}$

7. Field test- events used to evaluate performance in a non-controlled setting. ${ }^{47}$

8. Heme- A compound containing iron that is found in hemoglobin or myoglobin. ${ }^{11}$

9. Hemoglobin- A protein molecule with four subunits, each containing iron, responsible for oxygen transportation through the body. ${ }^{11}$

10. Iron Loss- Iron excreted from the body through menses, occult blood loss or other blood loss means.

11. Iron Status- $-^{3,6,21}$

Iron Deficiency- A state of decreased serum ferritin in the body. Iron Deficiency Anemia- A state of decreased serum ferritin and decreased hemoglobin in the body.

12. Myoglobin- A protein molecule structurally similar to hemoglobin found in muscle tissue. $^{3}$

13. Performance- Measures associated with athletic ability including, but not limited to event race times and rate of perceived exhaustion.

14. RPE- Rate of perceived exertion.

15. Transferrin- A protein that binds and transports iron between storage (ferritin) and other body tissues. 
16. $\mathrm{VO}_{2}$ max- maximal oxygen uptake of the body. ${ }^{48}$

\section{Limitations}

1. Data collected is from a single institution and sport, therefore the results may not be generalizable to other sports and levels of competition.

2. Sample size is relatively small.

3. Bloodwork is obtained from medical records and the reliability of obtaining these measures is unknown.

4. Data collected is from a single season, so the results may differ in different seasons as training levels differ throughout the yearly training cycles.

5. Data is extrapolated from race times rather than controlled testing.

\section{Significance of Study}

Ferritin is a widely used biomarker to determine iron status of the body and is used with other biomarkers such as hemoglobin to determine iron deficiency. Recently, ferritin has been used as a predictor of aerobic performance based on the role as an indicator of iron status. However, little research has been conducted thus far to observe if ferritin alone can be a predictor of field performance. While iron deficiency has been linked to decreased $\mathrm{VO}_{2}$ max, a laboratory test, little has been observed to show if this translates to field performance in female distance runners.

As athletes continue to look at ways to predict and enhance performance, ferritin has been a measure some institutions observe to gauge health and fitness. To date, there has been no single study to look at the validity of this method. While iron deficiency has long been linked to decreased performance, it is unclear if observing ferritin levels alone are enough to predict field performance. If so, is there a specific range, or cutoff point in which athletes' performance substantially decrease or increase? 
If a correlation between ferritin and field performance is found to exist, then it can guide the practitioner to make more appropriate decisions or anticipate issues if an athlete is found to have low levels of ferritin as it may relate to overtraining.

The importance of iron to the human body is paramount as it is needed for nearly 200 biologic functions. In cases of iron deficiency anemia, general health effects are more devastating and if related to over-training, addressing a trend in decreasing ferritin levels can be beneficial for long-term health and preventing additional time loss. This information will be disseminated to athletic trainers and the medical community via workshops and publications in anticipation for stimulating further research and best clinical practice. 


\section{APPENDIX B \\ LITERATURE REVIEW}

Iron and Importance

Iron is a fundamental element critical for many biological processes including oxygen transport, adenosine triphosphate production, electron transport chain, and red blood cell production. Iron is required for nearly 200 biologic functions in total throughout the body. ${ }^{3}$ The human body contains roughly 3 to 5 grams of iron depending on factors related to size, sex, and age and is the most abundant trace element found in the body. ${ }^{8,12,24}$ Red blood cells, which account for 2.5 to 3 grams of iron in the body, have a lifespan of 120 days. ${ }^{21}$ Hemoglobin, the iron-rich protein found in red blood cells, is responsible for the binding of oxygen, while the red blood cell acts as the vehicle to distribute the oxygen to various organs and other tissues. ${ }^{8,12,21}$ Erythropoiesis occurs in the bone marrow when sufficient iron levels are present. Because endurance distance runners exercise in a prolonged aerobic state, the uptake and carrying capacity of oxygen appear extremely important. Without sufficient iron to produce hemoglobin, the fewer erythrocytes the body can generate, and thus decreases the oxygen-carrying capacity of the body. With the body not able to utilize oxygen for aerobic pathways, the body must resort to other means of producing energy. The body then resorts to less performance-sustainable pathways.

Iron Deficiency and Etiology

Iron deficiency is the most common nutritional deficit worldwide affecting over one billion people. ${ }^{9}$ It affects roughly one in five Americans and one in four people globally. ${ }^{9}$ This condition is prevalent in athletes, particularly in females and even more so in female endurance distance runners. ${ }^{3,10}$ Incidence rates for female endurance runners range from 20 to $50 \% .{ }^{3,10}$ The 
condition exists on a continuum from iron depletion, iron deficiency nonanemia, and iron deficiency anemia. One of the most common criterium used to diagnose iron deficiency is a ferritin concentration of $20 \mathrm{ng} / \mathrm{mL} .{ }^{24}$ To determine the presence of anemia, hemoglobin concentration is measured, and a decrease of hematocrit occurs. ${ }^{7}$ The most severe form of iron deficiency, iron deficiency anemia, affects 3-5\% of women in the United States. ${ }^{7}$

Iron intake. When iron intake is inadequate, iron consumption must be increased to counteract an eventual negative iron balance. ${ }^{3,6,9,10,12}$ This leads to two options: eating iron-rich foods or taking a dietary supplement. ${ }^{6,14,49}$ Because there are two types of iron, dietary choices often need to consider in the foods being consumed. Heme iron is found in animal-based sources and is in the form the body can readily use once absorbed. There is minimal synthesis needed and has a bioavailability of $15 \%-35 \%{ }^{2,3}$ The mechanism for absorption non-heme iron is found in plant-based sources and requires additional synthesis so the iron can be used to create hemoglobin. The bioavailability of non-heme iron is low at $2 \%-20 \% .^{2,3}$ For a dietary supplement, as little as $2 \%$ of iron consumed is then absorbed via the gastrointestinal tract. ${ }^{3}$

Regarding iron intake, there are generally two interventions to increase the body's various forms of iron: dietary changes and a dietary iron supplement. ${ }^{50}$ There have been many studies performed comparing effects of diet and iron levels on the general population. When it comes to comparing diet and iron levels in college-aged female endurance runners, the research is very limited. ${ }^{50}$ Long-term studies have found that supplementation of $100 \mathrm{mg}$ of ferrous iron per day can increase a low ferritin levels by $20 \mathrm{ng} / \mathrm{mL}$ over three months. ${ }^{51}$ The risks associated with over-supplementation is iron toxicity, development of hemochromatosis, and possibly cancer. $^{24}$ 
Anschuetz, et al. ${ }^{50}$ observed the effects of meal composition in running and non-running college students. The experimental design study included seven females with two female controls who were injured runners. Dietary counseling over a four-week period was not found to be effective collectively in a group of male runners, although individually there were several who made a major improvement of their overall iron status. The authors extrapolated from their data that when observing iron status, dietary intake should not be considered in isolation. This is consistent with most current literature taking a global perspective on iron deficiency. ${ }^{3,9,10,12}$ The investigator went on to state the importance of absorption. Without absorption, intake becomes increasingly irrelevant. There is a saturation point of iron absorption with only $2-20 \%$ of nonheme iron being absorbed and 5-35\% of heme iron being absorbed during any given intake of food. ${ }^{50}$ Dietary influences can also change the overall absorption of iron. ${ }^{50}$ For example, in the absence of vitamin $\mathrm{C}$, iron absorbability decreases to $10 \% .{ }^{50}$ However, despite this saturation point, some foods, breakfast cereals for example, are overly fortified with elemental iron.

Alaunyte, et al. ${ }^{49}$ observed the effects of a cereal-based intervention in a study where onethird of the subjects were iron deficient. Cereal is often fortified with various vitamins and minerals, including iron, for dietary supplementation. The study included 11 participants in the six-week intervention, which reported significant improvement in iron intake, however the overall iron status did not improve. The authors asserted that the lack of substantiated results was potentially due to a high baseline of serum ferritin but was not recorded.

The negative effects of iron deficiency and iron deficiency anemia on performance are well documented. ${ }^{3,9,10,12,26}$ The effects of iron supplementation are often assumed to have a direct positive effect, increasing performance. Klingshirn, et al. ${ }^{26}$ observed objectified markers of endurance performance in iron deficient nonanemic female runners through an experimental 
design study. To assess performance, lactate threshold, oxygen consumption $\left(\mathrm{VO}_{2} \mathrm{max}\right)$, and respiratory exchange were observed. These variables are among the most widely observed in determining aerobic performance of the body. ${ }^{26}$ Following an eight-week supplementation with ferrous sulfate (the most commonly selected iron supplement for its low cost, moderate elemental iron makeup, and minimal side effects $)^{14}$ there was an increase in performance across the variables included. Both early-stage iron deficiency and iron deficiency anemia were not observed and noted to be insufficiently investigated in human subjects, suggesting this is where additional research could be done. ${ }^{26}$

Iron absorption. In the case of an absorption problem, the gastrointestinal tract can be bypassed, and supplementation can occur intravenously or intramuscularly. ${ }^{21}$ One potential issue with this route is that if an underlying condition is causing the deficiency, the athlete may regress back to an iron-deficient state. Studies observing ferritin after intravenous or intramuscular iron supplementation consistently report an increase in ferritin, but no studies were found observing a correlation between increased ferritin levels and increased performance in female endurance runners.

Absorption plays a big factor in whether an intervention is successful or not in an irondeficient patient. Genetics, age, gender, and gastrointestinal disorders can affect one's ability to absorb nutrients. ${ }^{6,15,49}$ If a patient is unable to increase iron stores in the body through oral supplementation, the absorption factor can be bypassed via intravenous or intramuscular supplementation. ${ }^{15,27,52}$

For intravenous iron supplementation, an iron infusion is performed. Because rapid changes in iron levels in the body can be harmful to the organs, the procedure is typically staged over multiple treatment sessions each lasting several hours. Woods et al. ${ }^{15}$ observed recovery 
measures such as mood disturbance and perceived fatigue when supplemented via intravenous injection. Ferric-carboxymaltose injections were chosen as the intervention. Perceived fatigue and mood disturbances decreased over four weeks. With intravenous supplementation, performance is slightly increased for an endurance distance event. ${ }^{26}$ In a sprint or repeat-sprint events, performance does not appear to increase. While there is a positive effect on the perception of recovery, intravenous supplementation is not shown to increase overall performance. In selecting an intravenous or intramuscular iron supplement, there is not as wide of a selection compared to an oral iron supplement. ${ }^{26}$

Strong evidence exists that iron depletion leads to decreased performance. However, iron repletion does not have as strongly related evidence in the case of increased performance. Burden et al. ${ }^{53}$ employed a double-blind randomized control study to test this hypothesis secondary to observing a hepcidin and iron metabolism response through a single high-dose iron intravenous injection. They discovered there was an initial increase in ferritin within the first 24 hours; however, after four weeks post-intervention, the levels were returned to that during preintervention.

Schröder et al. ${ }^{27}$ found that the high doses of intravenous iron supplementation are associated with relatively few short-term adverse effects. The research conducted noted unremarkable changes to vitals and ECG over the course of the intervention. The iron sucrose intravenous injection was infused into each patient over 3.5 hours to allow the body to gradually acclimate to $7 \mathrm{mg}$ of iron per kilogram of body mass entering the body. The inclusion criteria limited subjects to those with gastrointestinal bleeding as the cause of his/her subsequent iron deficient state. In all, ten participants were included in the study with not withdrawals. No 
studies were found that observed intravenous injection in subjects of a different specific iron deficient population subgroup.

Fatigue is one of the most common presentations of a patient with an iron deficiency or iron deficiency anemia. ${ }^{3,52}$ Krayenbuehl et al. ${ }^{52}$ observed ferritin with other iron-related levels, and intravenous supplementation. Over a week, a course of Venofer was intravenously injected into each patient. After six weeks of Venofer being administered intravenously, subjects had a significant improvement over fatigue and an increase in ferritin levels. The researchers reported statistical significance in both of these and recommended the intervention be applied to the targeted population.

Iron loss. If iron intake or absorption is outpaced by iron loss, an iron deficient state is inevitable. This is typically the result of blood loss through the gastrointestinal tract or through menses. ${ }^{22,23}$ For an endurance runner, gastrointestinal distress leading to occult blood loss is not an uncommon occurrence. ${ }^{23}$ In the female endurance runner population, menses become increasingly important when considering blood loss. ${ }^{22}$ Robertson et al. ${ }^{23}$, observed blood in stools both pre-marathon and post-marathon runners. Runners often experience gastrointestinal hemorrhaging due to the strain on the intestines. ${ }^{23}$ Other reasons why runners experience this bleed is explained by ulcerative colitis, polyps, anal fissures, or over-the-counter drug use. ${ }^{10,23}$ One study found that 20 out of 33 elite runners were found to have blood in their stools following a race. It is not evident what percentage of the body's blood is truly lost through the gastrointestinal tract and if this can account for a substantial loss affecting iron levels.

Another source of blood loss that is extremely common is menstrual bleeding. Bruinvels, et al. ${ }^{22}$ in a 2016 survey-based study found that $67 \%$ of elite exercising females had experienced heavy menstrual bleeding at some point. ${ }^{22}$ Over half of which developed anemia and over $80 \%$ 
using iron supplementation at some point. ${ }^{22}$ The study went to quantify "heavy menstrual bleeding" as $80 \mathrm{ml}$ or more of blood loss per cycle. This is the first study of its kind found to quantify a blood loss amount; however, being an online survey-based study, limitations exist in the accuracy of gathering this data. ${ }^{22}$

Chowdhury et al. ${ }^{54}$ employed a cohort study observing the effect of fecal occult blood loss in the presence of an iron deficiency and the ability of the body to predict means of determining gastrointestinal cancer. Two-hundred ninety-two subjects completed the study and while the study observed cancer as the dependent variable, this provides a broad reminder that this issue, however seemingly simple, can have devastating complications if left untreated. Blood loss accounts for the third source of issues in iron deficiency. Blood loss can be a result of gastrointestinal distress, menses, or be comorbid with an underlying gastrointestinal condition or disease.

Iron homeostasis in endurance runners following exercise appears paradoxical. Serum iron levels following endurance runs can remain unchanged or elevated up to two weeks following a distance race. Biomarkers related to oxidative stress are increased following distance runs. Ferritin levels do not change within the first 48 hours post-race. ${ }^{55}$ When observing marathon runners, erythrocytes, hemoglobin, and hematocrit levels decrease between days two and nine post-run. ${ }^{55}$ Previous literature has suggested a causative relationship exists of iron deficiency on aerobic performance, however current literature is challenging the notion that iron deficiency is the cause in athletes.

Iron Supplementation

In distance runners who are iron deficient or iron deficient anemic, supplementation has been shown to improve performance and endurance capacity in both men and women. In 
distance runners who are not iron deficient, however, supplementation does not have any beneficial effect on performance. ${ }^{14}$ Periodic supplementation in runners who are iron sufficient may prevent future incidence of iron deficiency, but there is little support that consistent supplementation in runners who are iron sufficient experience improved performance. ${ }^{24,25}$ Recommendations for iron testing is to obtain bloodwork once or twice per year to determine iron status and begin, maintain, adjust, or discontinue any iron intervention. ${ }^{24}$

Guidelines for iron supplementation varies greatly. There is no consensus on the type or dosage of supplementation in runners who are nonanemic. Studies conducted in this area used different methodology and obtained mixed results. ${ }^{25}$ Treatment options are often considered based on a multitude of factors. Previous diagnosis, pertinent medical conditions, severity of iron deficiency, and risk of treatment is used to determine the appropriate treatment. Conservative treatment options like oral iron supplementation are selected initially because they are costeffective and low-risk. ${ }^{11}$ Ferrous sulfate is primarily used due to its wide availability and effectiveness. Adverse effects such as constipation or gastrointestinal stress occurs in $\sim 10 \%$ of the general population. Ferrous gluconate or ferrous fumarate may be used in these cases. Supplementation with these options may benefit patients by having slow-release properties, however less iron may be absorbed. ${ }^{11}$

Iron deficiency and iron deficiency anemia are found to have detrimental effects on performance and health., ${ }^{7}$ Iron deficiency inhibits energy efficiency and overall endurance capacity in runners. ${ }^{7,48}$ Iron deficiency anemia inhibits $\mathrm{VO}_{2}$ max specifically and is proportional to the decrease in hemoglobin. ${ }^{7,12}$ With the body not able to utilize oxygen for aerobic pathways, the body must resort to other means of producing energy, which are less performance-sustainable pathways. This cascading effect results in a decrease of oxygen uptake, increase of blood 
products, decrease in performance, increase in fatigue, and prolonged recovery. ${ }^{12}$ Athletes are often considered to be more at-risk than the general population, however incidence rates between the two populations are similar. Decreased hemoglobin levels paired with decreased ferritin levels are often observed in the presence of increased plasma volume as an adaption to endurance training. ${ }^{12}$ This creates delusional psuedoanemia often seen in athletes since concentration values of both ferritin and hemoglobin are decreased. ${ }^{12}$

Performance and Distance Runners

Performance can be measured in many ways. When observing sport performance, intensity is often used and classified to measure performance. To measure intensity, tests often used include a specified distance where heart rate and blood lactate levels are measured. ${ }^{47,48} \mathrm{An}$ increase in intensity is often considered an increase in performance. Trained endurance runners are able to experience sustained levels of performance while intensity is maintained or changed incrementally over time. In distance running, performance is determined by aerobic capacity. During consistent pace running, there is a linear relationship between $\mathrm{VO}_{2}$ max and heart rate. This is considered an appropriate indicator of exercise intensity in an untrained endurance runner. For team sports, where anaerobic pathways are utilized primarily during sprinting or jumping movements, this is not an appropriate indicator. ${ }^{47}$

The most common test to measure aerobic capacity through oxygen consumption is the $\mathrm{VO}_{2}$ max test, developed in 1970 . The test is designed to have the subject reach maximal exertion quickly and determine oxygen consumption at that point. In animal studies, $\mathrm{VO}_{2}$ max decreases linearly with decreased hemoglobin concentration. ${ }^{49}$ In a review of various studies, it was determined most protocols were of poor design by having subjects operate in an aerobic glycolysis state. This inherent limitation of the $\mathrm{VO}_{2}$ max test makes the results less generalizable 
for competitive endurance runners. Four studies exist, three animal and one human, observing iron deficiency of all levels and voluntary physical activity ${ }^{49}$ All support causal evidence, but measures used to evaluate the data varied between studies. ${ }^{49}$ When observing iron deficiency without anemia, there is mixed evidence that aerobic capacity is substantially inhibited.

Means to measure physical activity and performance have been developed for decades. Borg's Rate of Perceived Exertion (RPE) scale was developed in 1960's and is intended to measure relative work intensity. ${ }^{57}$ Previous research established a relationship between external work intensity and oxygen uptake. It was postulated that a scale could be developed to determine oxygen uptake from subjective measurements of work intensity. ${ }^{57}$ Borg's RPE scale is a 15-point Likert-type scale ranging from 6-20. ${ }^{57}$ Since its development, the RPE scale has been used extensively throughout research to determine $\mathrm{VO}_{2}$ max and lactate threshold typically during a graded treadmill run or cycling session. ${ }^{58,59}$ However, studies observing the validity and reliability of the scale have produced mixed results. Being a subjective measurement, RPE can be influenced by many factors, notably environmental. RPE collection following exercise may vary depending on ambient temperature, people present, fitness level, music, or feedback. ${ }^{60}$ Interestingly, factors not affecting RPE is perception of fatigue, stress, and sleep during a submaximal 10-minute training session. ${ }^{60}$ Many of these studies observe specific populations such as industrial workers or adolescents making the results ungeneralizable to endurance athletes in a field setting. In many studies observing sub-elite endurance athletes, RPE appears to be a useful tool in determining levels of performance and for predicting $\mathrm{VO}_{2}$ max utilization. Various versions of Borg's RPE scale have been adapted which have been supported through empirical findings. A considerable factor affecting results finding reliability and validity of Borg's RPE scale is the protocol used. ${ }^{38}$ In a systematic review, RPE was not as reliable with 
elite distance runners compared to nonelite athletes suggesting more sensitive testing is required for highly trained athletes who have developed adaptations from aerobic performance. ${ }^{38}$ Additionally, $\mathrm{VO}_{2}$ max as a predictor of performance has been questioned. In a study observing race times, $\mathrm{VO}_{2}$ max was not a predictor of race performance in a 5000 meter race.${ }^{39}$ Race times are a direct objective measure of distance runners performance and often the focus of determining performance. More research is needed observing race performance rather than laboratory studies with treadmill or cycling progressions to determine the usefulness of $\mathrm{VO}_{2}$ max and RPE as measures of performance in female endurance athletes.

Other Variables That Affect Performance

Performance is influenced by many factors both intrinsically and extrinsically. Cellular level changes allow for larger systemic function to adapt over time. Much of the research observing and measuring sport performance is from team sports where anaerobic pathways are utilized repetitively over time. As training level increases, such as in the case of elite or collegiate runners who experience higher training loads, conventional tests measuring performance are not valid measure for indicating performance. Recent studies finding no significance for $\mathrm{VO}_{2}$ max in predicting field performance in trained endurance runners suggested tissue oxidation may be responsible for increased performance. ${ }^{55}$

Nutritional consideration is another major factor affecting performance. Nutrition has long been identified as a factor of performance. Proper nutrition is important for development and maturation in adolescents and to achieve high athletic performance. Athletes require additional energy to meet the demands of their sport. Intake must meet expenditure to maintain energy balance. ${ }^{30}$ With a negative energy balance, development and performance may become inhibited. Female cross country runners or endurance athletes are commonly seen as a high-risk 
group for eating disorders. Physical appearance and body image can exacerbate the issue of inadequate nutrient intake. Eating disorders are pervasive in collegiate female distance runners. In 2016, 27.2\% of collegiate female distance runners reported suffering from an eating disorder either currently or in the past compared with $6.3 \%$ of collegiate male distance runners. ${ }^{31}$ Nearly $70 \%$ of female respondents reported their weight affected the way they felt about themselves. ${ }^{31}$ Despite eating disorders being prevalent in collegiate female distance runners, nearly all female collegiate athletes are found to have inadequate intake for their energy needs. ${ }^{30}$ Inadequate intake results in lower levels of metabolic functions and decreased micronutrients needed for the body to maintain homeostasis. ${ }^{32}$ As intake decreases, aerobic performance is found to decrease since metabolic pathways become impaired. ${ }^{32}$

Hydration is yet another factor often considered to affect and be a determinant of performance. Being well-hydrated prior to exercise and fluid replacement during exercise is important to preventing decreased performance. The American College of Sports Medicine published an updated position stand in 2007 on dehydration in athletes and defined dehydration as $2 \%$ body weight loss, stating that any loss greater than $2 \%$ degrades aerobic performance in warm to hot environments. ${ }^{33}$ The goal for endurance athletes is to prevent a $2 \%$ loss from occurring during exercise. Hypohydration of $2.6 \%$ to $5.6 \%$ of body weight prior to activity impairs high intensity activity lasting 5 to 30 minutes. ${ }^{34}$ Oxygen consumption is further decreased at a rate of $2.9 \%$ for every percent body weight lost beyond $3.1 \% \cdot{ }^{34}$ Recently, five laboratory studies simulating real-world conditions found no impairment to endurance performance from exercise-induced body weight loss. ${ }^{34}$ These studies challenged the findings of those used to establish the $2 \%$ body weight loss during exercise, suggesting the research protocols did not simulate real-world conditions. Contrary to the widely-accepted belief in the 
$2 \%$ body loss idea, research observing marathon runners found a direct relationship with body weight loss and race times, whereas body weight decreases, so do race times. It was noted the first four finishers had a mean weight loss of 5.8\%, well beyond the established $2 \%$ value. $^{34}$

There is a debate between forced fluid replacement and ad libitum fluid replacement, drinking when signaled by thirst. New recommendations suggest establishing a well-hydrated state prior to exercise, but only consuming fluids ad libitum during exercise. ${ }^{34}$ Consumption of fluids during exercise have been shown to cause gastrointestinal distress, thereby decreasing performance. As the paradigm shifts on hydration, particularly in regard to endurance activities, recommendations are likely to follow once well-established research show consistent findings.

Other factors affecting performance include stress and sleep. Sleep is an important component to performance and is widely accepted as such through empirical evidence. ${ }^{35}$ Speed and endurance are both inhibited when two or more hours of sleep is lost. Another result of sleep loss is the increase in injury and illness risk. Athletes receiving less than eight hours of sleep per night are at an almost doubled chance of suffering a significant injury. Besides direct effects on athletic performance, sleep can also create weight issues, mood disturbances, and increased stress. ${ }^{35}$ Research observing collegiate female distance runners and sleep is limited. In a study observing ultramarathon runners, sleep disorders were found in nearly $40 \%$ of females. ${ }^{36}$ Most ultramarathon runners reported receiving six to eight hours of sleep during weekdays and seven to nine hours on weekends and holidays. ${ }^{36}$ Research observing aerobic performance impacted by circadian rhythm revealed mixed results of exercise occurring at different times throughout the day. ${ }^{37}$ Interestingly, anaerobic performance was found to not be impacted by sleep deprivation, while aerobic performance was affected and multiple studies have found similar findings. ${ }^{37}$ 
A variety of psychometric tools have been created to capture factors related to stress, recovery, and sleep. ${ }^{61,62}$ The RESTQ-Sport was developed as a recovery-stress questionnaire containing questions related to recovery, stress, and sleep. In its original form, the questionnaire contained 76 items on a Likert-type scale with different sections of questions receiving a weighted score. More recently, a shorter version of the questionnaire contained 52 items and a subsequent 36 -item version was released making for easier administration. The 36 -item version has been evaluated for reliability and validity as a whole in addition to individual questions. ${ }^{62}$ Summary

The importance of iron is pervasive in all living organisms in order to function. One often observed function of iron is its role in erythrocyte production for oxygen carrying abilities. Although the importance of iron is evident, iron deficiency remains the most common nutritional deficit. Iron intake, absorption and loss can all contribute to iron deficiency if the underlying cause is left unresolved. Ferritin is used to diagnose iron deficiency; however, it is unclear as to whether ferritin levels can be used to determine measures of performance. Due to the tight regulation of iron in the body, oral supplementation is recommended due to the low risk of reaching toxic levels. In extreme cases, parenteral supplementation may be used, but athletes should be monitored closely. Iron deficiency has long been associated with decreased energy levels and performance. The complex relationship between iron and performance, recovery, and sleep are, at best, moderately understood. Observation of sex, endurance versus non-endurance, and level of competition is necessary to delineate the effect of iron on performance between groups. 


\section{APPENDIX C}

\section{ADDITIONAL METHODS}

Table C1. Informed Consent

\section{Only Minimal Risk Consent Information and HIPAA Form}

Principal Investigator

Department

Protocol Number

Study Title

Co-Investigator(s)

\author{
Michelle Sandrey, PhD, ATC
}

College of Physical Activity and Sport Sciences

TBD

Ferritin: The Iron Deficiency Biomarker in Collegiate Female Distance Runners Ty Bigelow, LAT, ATC

\section{Contact Persons}

In the event you experience any side effects or injury related to this research, you should contact Dr. Michelle Sandrey at (304) 292-0870 or at msandrey@mail.wvu.edu or Ty Bigelow at (540) 454-4248 or at ty.bigelow@mail.wvu.edu. If you have any questions, concerns, or complaints about this research, you can contact Dr. Michelle Sandrey at (304) 2920870 or at msandrey@mail.wvu.edu or Ty Bigelow at (540) 454-4248 or at ty.bigelow@mail.wvu.edu.

For information regarding your rights as a research subject, to discuss problems, concerns, or suggestions related to the research, to obtain information or offer input about the research, contact the Office of Research Integrity and Compliance at (304) 293-7073.

In addition, if you would like to discuss problems, concerns, have suggestions related to research, or would like to offer input about the research, contact the Office of Research Integrity and Compliance at 304-293-7073.

\section{Introduction}

You, by , have been asked to participate in this research study, which has been explained to you Investigator, Dr. Michelle Sandrey and Co-investigator, Ty Bigelow in the Department of College of Physical Activity and Sport Sciences at West Virginia University. This research is being conducted to fulfill the requirements for Thesis in the College of Physical Activity and Sport Sciences at West Virginia University under the supervision of Dr. Michelle Sandrey.

\section{Purpose(s) of the Study}

The purpose of the study is to determine how ferritin levels relate to measures of performance and recovery, as well as the relationship between iron supplementation and ferritin and hemoglobin levels.

\section{Description of Procedures}


Previous existing data will be used related to ferritin levels, hemoglobin levels, and race times. Ferritin and hemoglobin levels are regularly obtained four times a year. Race times will be obtained through the university's Department of Intercollegiate Athletics Sports Information Office and publicly posted results online. Data collected during this study will be by collecting two self-reported questionnaires. A demographic questionnaire will take approximately 10 minutes to complete and will include items related to iron deficiency, iron supplementation, and injury history. A post-race questionnaire will be administered following each of the seven scheduled indoor track meets and will include items related to stress, exertion, and recovery. This will take approximately 5 minutes to complete. You do not have to answer all the questions. You will have the opportunity to see the questionnaire before signing this consent form.

\section{Discomforts}

There are no known or expected risks from participating in this study, except for the mild frustration associated with answering the questions.

\section{Alternatives}

You do not have to participate in this study.

\section{Benefits}

You may not receive any direct benefit from this study. The knowledge gained from this study may benefit you by better understanding any relationship of ferritin to performance. The knowledge gained from this study may eventually benefit others.

\section{Financial Considerations}

There is no financial compensation by being a participant in this study.

\section{Confidentiality}

Any information about you that is obtained as a result of your participation in this research will be kept as confidential as legally possible. Your research records and test results, just like hospital records, may be subpoenaed by court order or may be inspected by the study sponsor or federal regulatory authorities without your additional consent.

In any publications that result from this research, neither your name nor any information from which you might be identified will be published without your consent.

\section{HIPAA}

We know that information about you and your health is private. We are dedicated to protecting the privacy of that information. Because of this promise, we must get your written authorization (permission) before we may use or disclose your protected health information or share it with others for research purposes.

You can decide to sign or not to sign this authorization section. However, if you choose not to sign this authorization, you will not be able to take part in the research study. Whatever choice you make about this research study will not have an effect on your access to medical care.

\section{Persons/Organizations Providing the Information}

Patient

WVU Department of Intercollegiate Athletics

\section{Persons/Organizations Receiving the Information}


- $\quad$ The research site(s) carrying out this study. This includes West Virginia University Athletic Training Department and the College of Physical Activity and Sport Sciences

- $\quad$ The members and staff of any Institutional Review Board (IRB) that oversees this research study.

- West Virginia University Office of Research Integrity and Compliance and Office of Sponsored Programs.

\section{The Following Information Will Be Used}

Information from your existing medical records and new information about you that is created or collected during the study such as: iron deficiency, supplement use, clinic visit notes, laboratory results from already existing data, demographic data, and study forms.

\section{The Information is Being Disclosed for the Following Reasons}

- $\quad$ Review of your data for quality assurance purposes

- $\quad$ Publication of study results (without identifying you)

\section{You May Cancel this Authorization at Any Time by Writing to the Principal Investigator}

Dr. Michelle Sandrey, PO Box 6116, West Virginia University, Morgantown,WV 26506-6116

If you cancel this authorization, any information that was collected already for this study cannot be withdrawn. Once information is disclosed, according to this authorization, the recipient may redisclose it and then the information may no longer be protected by federal regulations.

You have a right to see and make copies of your medical records. You will not be able to see or copy your records related to the study until the sponsor has completed all work related to the study. At that time you may ask to see the study files related to your participation in the study and have the study investigators correct any information about you that is wrong.

This authorization will expire at the end of the study unless you cancel it before that time (or has a specific expiration date).

\section{Voluntary Participation}

Participation in this study is voluntary. You are free to withdraw your consent to participate in this study at any time.

Refusal to participate or withdrawal will involve no penalty to you. Refusal to participate or withdrawal will not affect your future care at West Virginia University.

In the event new information becomes available that may affect your willingness to participate in this study, this information will be given to you so that you can make an informed decision about whether or not to continue your participation.

You have been given the opportunity to ask questions about the research, and you have received answers concerning areas you did not understand.

Upon signing this form, you will receive a copy. 
I willingly consent to participate in this research.

\section{Signatures}

Signature of Subject

Printed Name

Date

Time

The participant has had the opportunity to have questions addressed. The participant willingly agrees to be in the study.

Signature of Investigator or Co-Investigator

Printed Name

Date

Time 
Table C2. Demographic Questionnaire

ID Number:

Date Completed:

\section{Demographic Questionnaire}

Thank you for your participation in this study. Please complete the questions below as accurately as possible. If any questions are unclear, please contact one of the investigators: Dr. Michelle Sandrey at msandrey@mail.wvu.edu or Ty Bigelow at ty.bigelow@mail.wvu.edu. While full completion of the questionnaire is appreciated, you may choose not to answer any question(s).

1. Age:

2. Race: (One or more categories may be selected)
$\square$ American Indian
$\square$ Black or African American
$\square$ White
$\square$ Other Race:

3. Years of sport participation prior to college (circle one): $\begin{array}{lllllllllll}1 & 2 & 3 & 4 & 5 & 6 & 7 & 8 & 9 & 10+\end{array}$

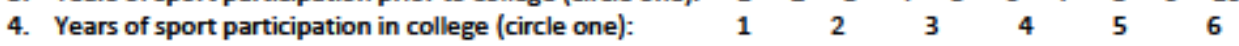

5. Have you ever formally been diagnosed with iron deficiency (circle one)? Yes / No

6. Do you take any iron supplements (circle one)? Yes $/$ No If yes, please answer $6 a-6 c$.

a. What iron supplement are you taking (ferrous sulfate, ferrous gluconate, etc.)

b. What is the dosage?

c. How often do you take it? (Once a day, twice a day, every other day, etc)

7. Have you suffered any injuries/illnesses in the previous year requiring you to miss more than a week from training? If so, please include injury and time spent not training.

8. Have you suffered any injury in which you lost more than three months off from training? If so, please include injury and time spent not training.

9. Are you currently taking or have taken birth control in the last 12 months? Yes / No

10. How many periods have you had in the last 12 months?

11. How would you describe your periods?
$\square$ Light
$\square$ Moderate
$\square$ Heavy
$\square$ Unsure or Varies

Thank you for your participation in this study. 
Table C3. Post-Race Questionnaire

ID Number:

Date Completed:

\section{Post-Race Questionnaire}

Please answer the following questions as honestly and accurately as possible.

1. In which event did you compete?

$\square 400 \mathrm{~m} \square 800 \mathrm{~m} \quad \square 1500 \mathrm{~m} \quad \square 1 \mathrm{mi} \quad \square 3000 \mathrm{~m} \quad \square 5000 \mathrm{~m}$ 口Other:

2. Rate of Perceived Exertion. Please circle the number.

\begin{tabular}{|l|l|}
\hline 6 & No exertion \\
\hline 7 & Extremely light \\
\hline 8 & \\
\hline 9 & Very light \\
\hline 10 & \\
\hline 11 & Light \\
\hline 12 & \\
\hline 13 & Somewhat hard \\
\hline 14 & \\
\hline 15 & Hard \\
\hline 16 & \\
\hline 17 & Very hard \\
\hline 18 & \\
\hline 19 & Extremely hard \\
\hline 20 & Maximal exertion \\
\hline
\end{tabular}

Please circle your level of agreement with each statement below.

\begin{tabular}{|l|c|c|c|c|c|c|}
\hline & $\begin{array}{l}\text { Strongly } \\
\text { Disagree }\end{array}$ & Disagree & $\begin{array}{l}\text { Slightly } \\
\text { Disagree }\end{array}$ & $\begin{array}{l}\text { Slightly } \\
\text { Agree }\end{array}$ & Agree & $\begin{array}{l}\text { Strongly } \\
\text { Agree }\end{array}$ \\
\hline 3. I felt adequately hydrated. & 1 & 2 & 3 & 4 & 5 & 6 \\
\hline 4. I felt adequately fueled. & 1 & 2 & 3 & 4 & 5 & 6 \\
\hline 5. I felt stress-free. & 1 & 2 & 3 & 4 & 5 & 6 \\
\hline 6. I felt well-rested. & 1 & 2 & 3 & 4 & 5 & 6 \\
\hline 7. I felt fatigued. & 1 & 2 & 3 & 4 & 5 & 6 \\
\hline 8. I performed well. & 1 & 2 & 3 & 4 & 5 & 6 \\
\hline 9. I was ill/injured. & 1 & 2 & 3 & 4 & 5 & 6 \\
\hline
\end{tabular}

10. Approximate hours of sleep last night (circle one).
$<3 \quad 3.5$
$4.5 \quad 5$
5.5
6.5

11. Average hours of sleep over the last three nights (circle one).

$\begin{array}{lllllllllllllll}<3 & 3.5 & 4 & 4.5 & 5 & 5.5 & 6 & 6.5 & 7 & 7.5 & 8 & 8.5 & 9 & 9.5 & >10\end{array}$ 


\section{APPENDIX D}

\section{ADDITIONAL RESULTS}

Table D1. Each participants' class status and preseason/postseason ferritin levels.

\begin{tabular}{ccccc}
\hline Participant & $\begin{array}{l}\text { Freshman/ } \\
\text { Upperclassman }\end{array}$ & $\begin{array}{l}\text { Preseason } \\
\text { ferritin (ng/ml) }\end{array}$ & $\begin{array}{c}\text { Postseason } \\
\text { ferritin }(\mathrm{ng} / \mathrm{ml})\end{array}$ & Difference \\
\hline 1 & Freshman & 54 & 42 & -12 \\
2 & Upperclassman & 86 & 77 & -9 \\
3 & Freshman & 197 & 159 & -38 \\
4 & Freshman & 41 & 49 & 8 \\
5 & Upperclassman & 30 & 30 & 0 \\
6 & Upperclassman & 37 & 40 & 3 \\
7 & Upperclassman & 38 & 38 & 0 \\
8 & Upperclassman & 65 & 69 & 4 \\
9 & Upperclassman & 40 & 21 & -19 \\
10 & Upperclassman & 62 & 51 & -11 \\
\hline
\end{tabular}

Table D2. Correlations between ferritin levels, measures of performance, recovery, and sleep.

\begin{tabular}{|c|c|c|c|c|c|c|}
\hline \multicolumn{2}{|c|}{ Control Variables } & & $\begin{array}{c}\text { Ferritin } \\
\text { Difference }\end{array}$ & $\begin{array}{c}\text { Felt } \\
\text { Hvdrated }\end{array}$ & $\begin{array}{c}\text { Felt } \\
\text { Fueled }\end{array}$ & $\begin{array}{l}\text { Felt Stress- } \\
\text { Free }\end{array}$ \\
\hline \multirow{17}{*}{$\begin{array}{l}\text { Total } \\
\text { Meets }\end{array}$} & \multirow{2}{*}{$\begin{array}{l}\text { Ferritin } \\
\text { Difference }\end{array}$} & Correlation & 1 & -0.255 & 0.119 & -0.106 \\
\hline & & Significance & & 0.065 & 0.398 & 0.451 \\
\hline & \multirow{2}{*}{ Felt Hydrated } & Correlation & -0.255 & 1 & 0.462 & -0.185 \\
\hline & & Significance & 0.065 & & 0.001 & 0.184 \\
\hline & \multirow{2}{*}{ Felt Fueled } & Correlation & 0.119 & 0.462 & 1 & -0.052 \\
\hline & & Significance & 0.398 & 0.001 & . & 0.713 \\
\hline & \multirow{2}{*}{ Felt Stress-Free } & Correlation & -0.106 & -0.185 & -0.052 & 1 \\
\hline & & Significance & 0.451 & 0.184 & 0.713 & \\
\hline & \multirow{2}{*}{ Felt Well-Rested } & Correlation & -0.091 & -0.068 & -0.051 & 0.322 \\
\hline & & Significance & 0.515 & 0.631 & 0.717 & 0.019 \\
\hline & \multirow{2}{*}{$\begin{array}{l}\text { Did Not Feel } \\
\text { Fatigued }\end{array}$} & Correlation & 0.027 & 0.117 & -0.123 & -0.126 \\
\hline & & Significance & 0.846 & 0.402 & 0.381 & 0.368 \\
\hline & \multirow{2}{*}{$\begin{array}{l}\text { Felt Performed } \\
\text { Well }\end{array}$} & Correlation & -0.149 & -0.04 & 0.121 & 0.238 \\
\hline & & Significance & 0.286 & 0.776 & 0.389 & 0.086 \\
\hline & \multirow{3}{*}{$\begin{array}{l}\text { Did Not Feel } \\
\text { Ill/Injured }\end{array}$} & Correlation & 0.421 & -0.155 & -0.107 & -0.07 \\
\hline & & Significance & $0.002 *$ & 0.267 & 0.445 & 0.618 \\
\hline & & Correlation & 0.094 & -0.045 & -0.037 & 0.05 \\
\hline
\end{tabular}




\begin{tabular}{llrrrr} 
Sleep Previous & Significance & 0.505 & 0.749 & 0.793 & 0.72 \\
Night (Hrs) & Correlation & 0.315 & -0.013 & 0.031 & 0.081 \\
Avg Sleep Prev & Significance & $0.021^{*}$ & 0.929 & 0.824 & 0.564 \\
3 Nights (Hrs) & Correlation & 0.407 & 0.013 & 0.165 & -0.231 \\
RPE & Significance & $0.002^{*}$ & 0.925 & 0.238 & 0.096 \\
\hline
\end{tabular}

Table D3. Correlations between ferritin levels, measures of performance, recovery, and sleep (continued).

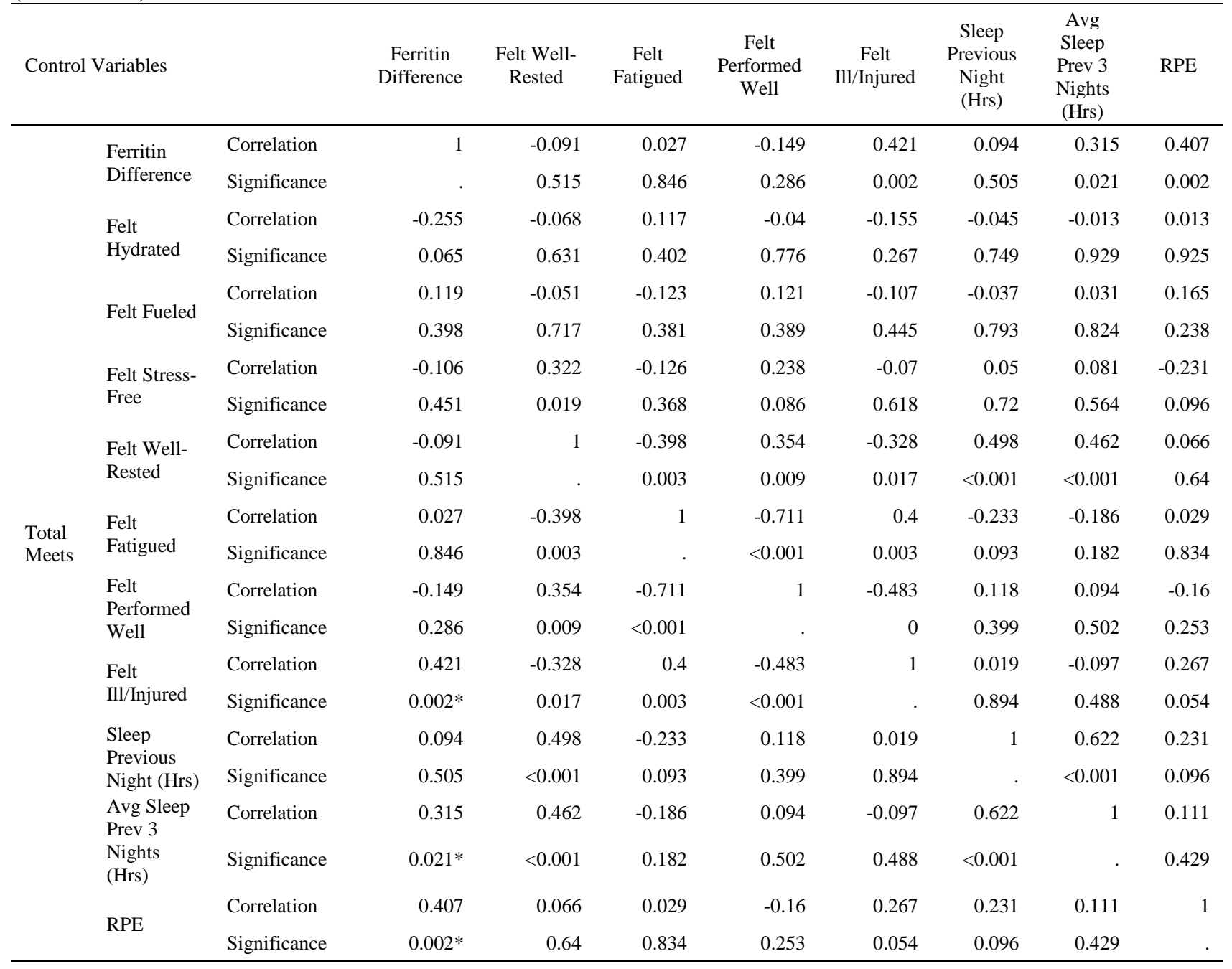


Figure D1. Mile race times over the indoor track and field season.

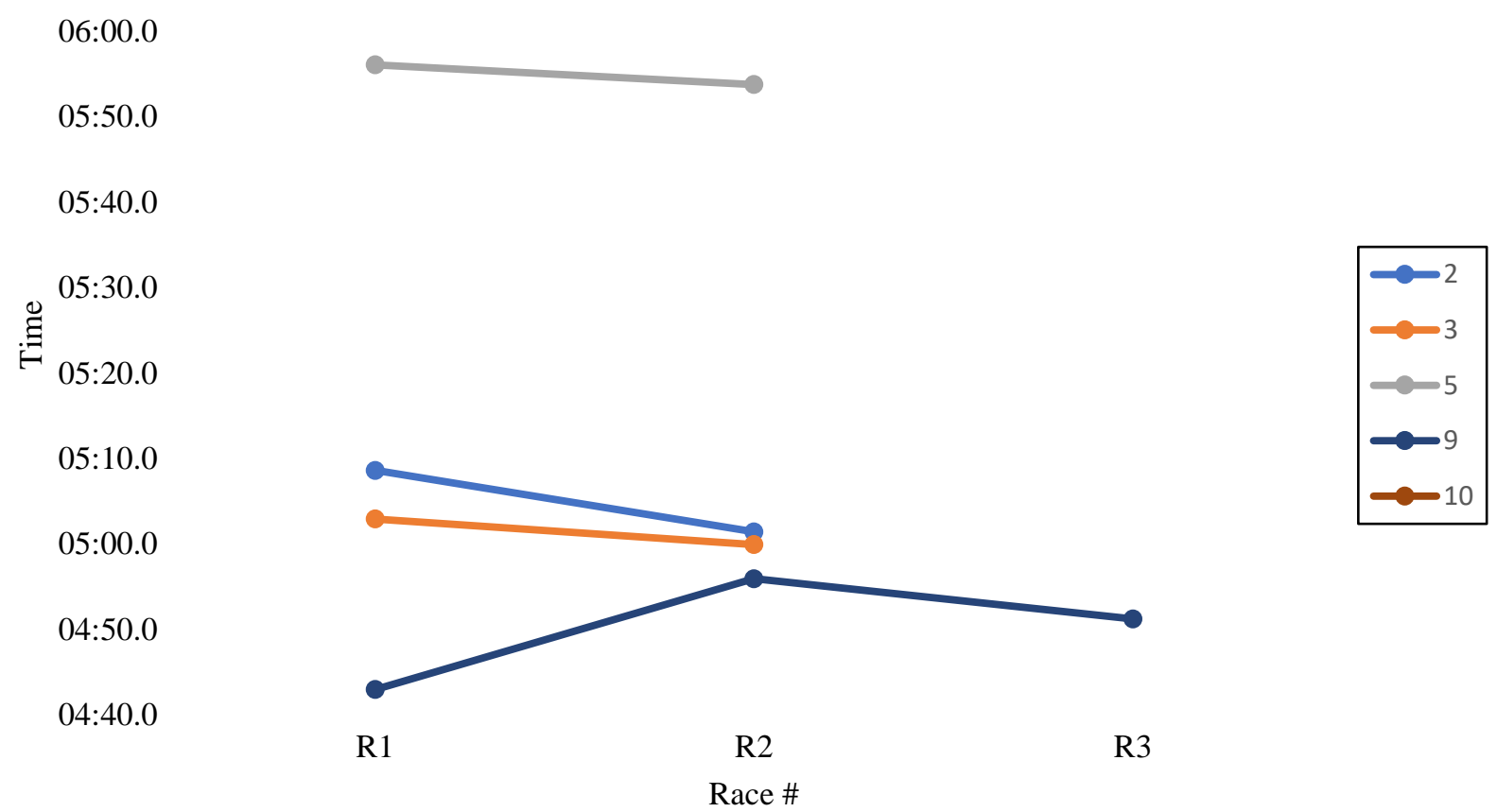

Figure D2. 3000 meter race times over the indoor track and field season.

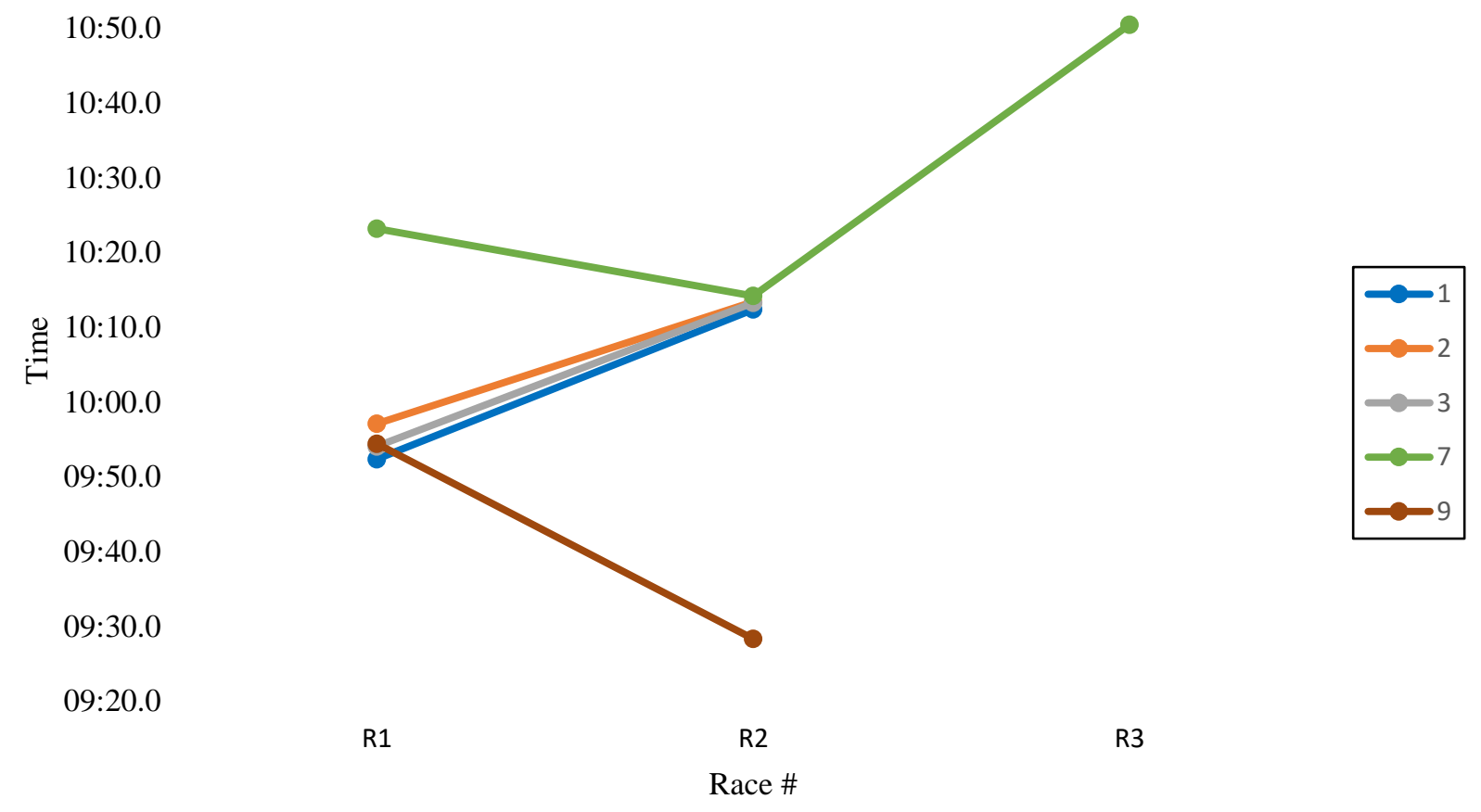


Figure D3. Average scores of post-race measures of performance and recovery.

3

2

1

0

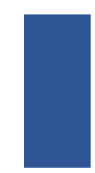

Hydrated

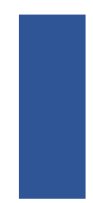

Fueled

$-1$

$-2$

$-3$

Figure D4. Freshman ferritin levels over three time points.

300
280
260
240
220
200
180
160
140
120
100
80
60
40
20
0

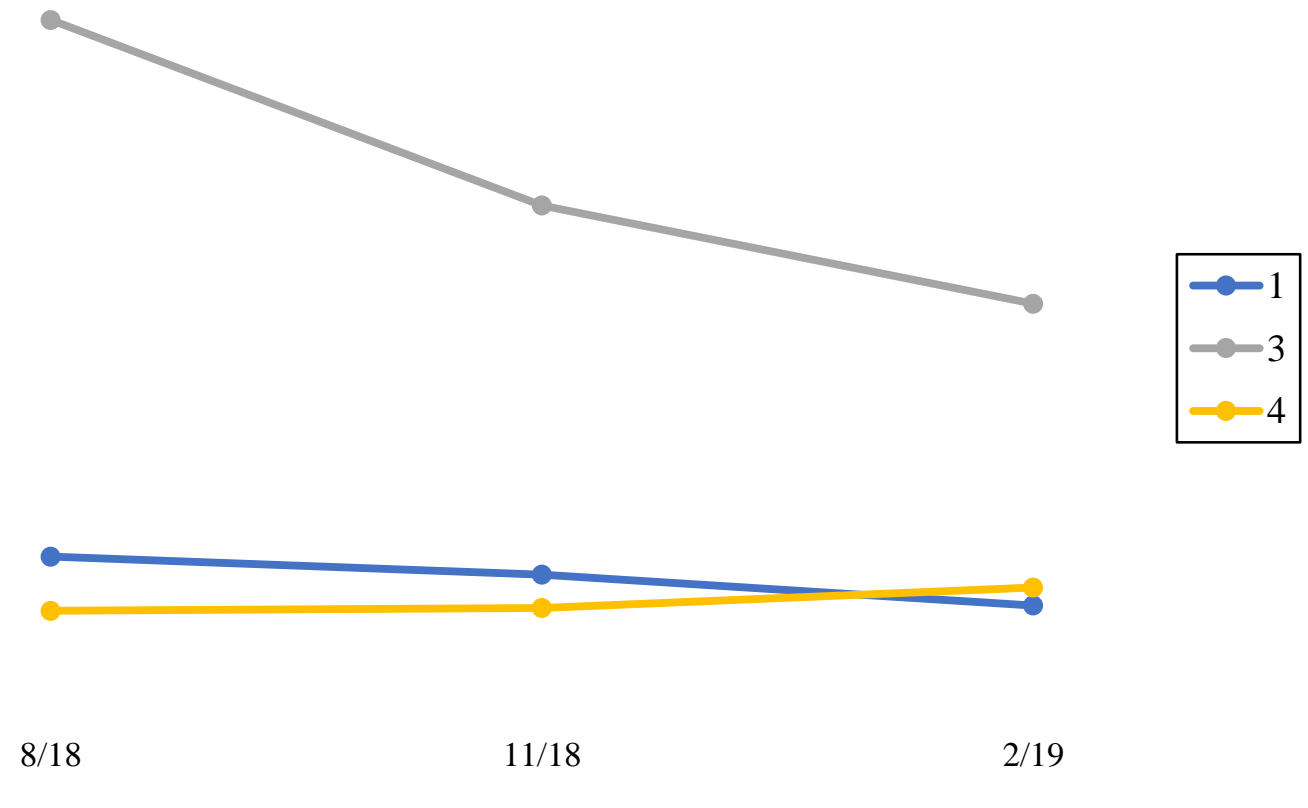

Stress-Free Well-Rested Not Fatigued Performed well Ill/Injured $-2$

$-3$

300

280

240

220

200

180

60

(40.0

120

100

60

20

0 
Figure. D5: Upperclassman ferritin levels over seven time points.

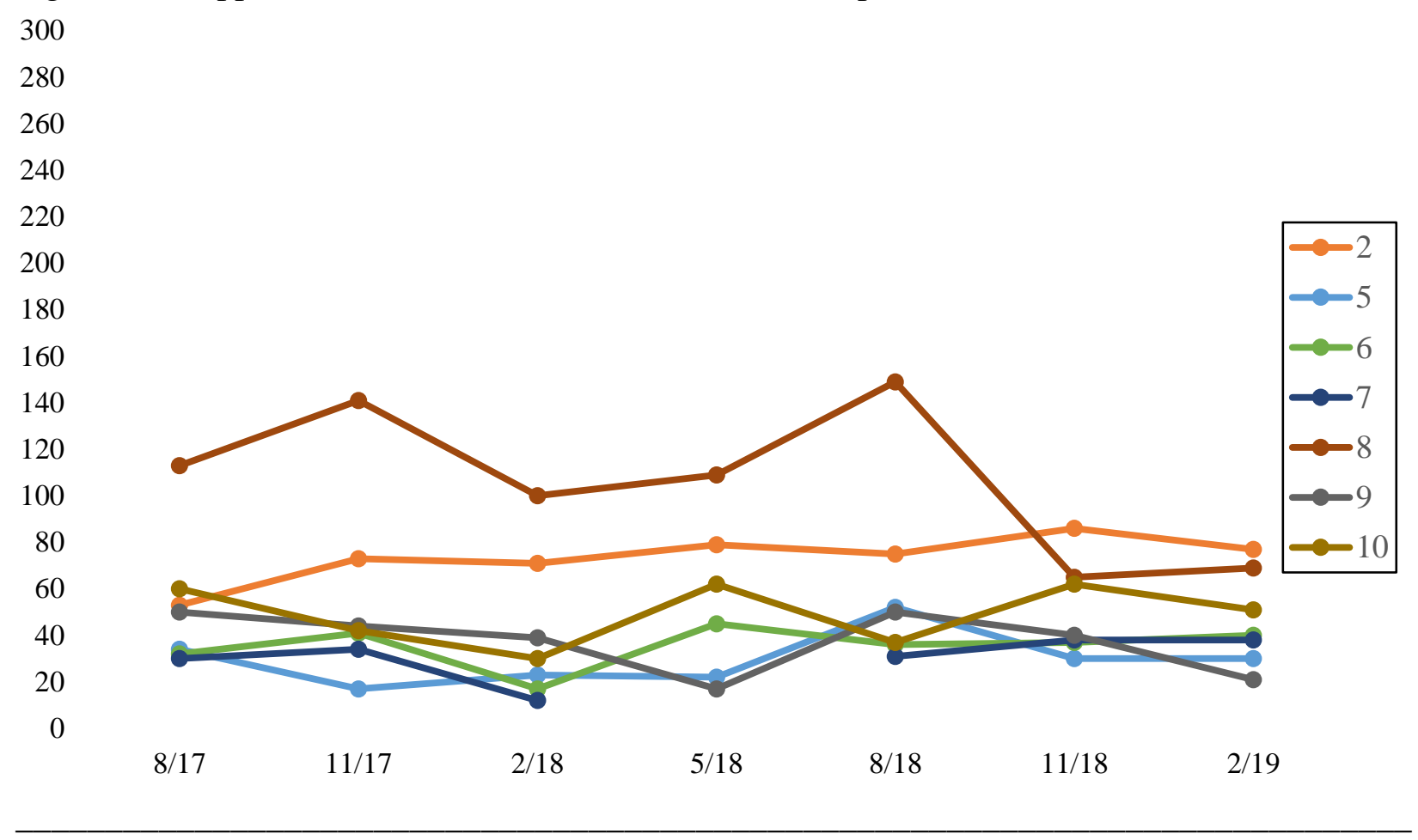

Figure D6. Average RPE scores over the indoor track and field season.

20

19

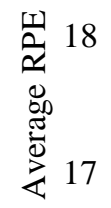

16

15

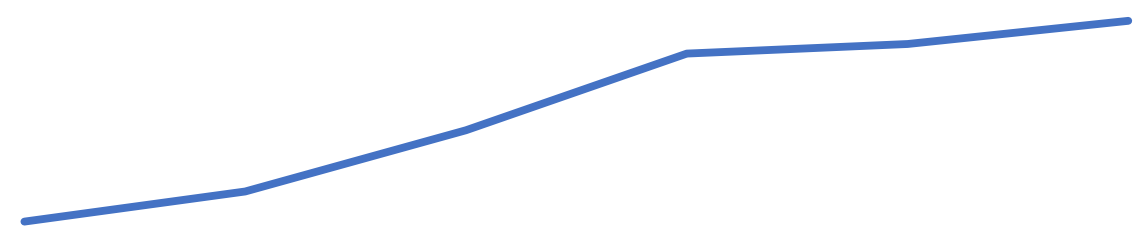

1

2

3

4

5

6

Meet \# 


\section{APPENDIX E \\ RECOMMENDATIONS FOR FUTURE RESEARCH}

1. Increase sample size to include more participants from other institutions and observe over a longer period to include other seasons which may affect ferritin levels based on training loads in various competition seasons.

2. Observe other endurance sport athletes to determine if ferritin levels are affected similarly to that of female distance runners.

3. Obtain demographic information at regular time points to determine if other factors are present which may affect ferritin levels over time.

4. Conduct ferritin and hematological biomarker testing prior to and following each meet to allow for better interpretation of ferritin levels related to competition.

5. Control for number of events competed, event distance competed, and training volume.

6. Control for supplementation to determine effects on ferritin levels as well as the magnitude of the effects. 


\section{ADDITIONAL REFERENCES}

42. Chung J, Wessling-Resnick, M. Molecular mechanisms and regulation of iron transport. Crit Rev Cl Lab Sci. 2008;40(2):151-182.

43. Wang W, Knovich MA, Coffman LG, Torti FM, Torti SV. Serum ferritin: Past, present and future. Biochim Biophys Acta. 2010;1800(8):760-9.

44. Nuviala RJ, Castillo MC, Lapieza MG, Escanero JF. Iron nutritional status in female karatekas, handball and basketball players, and runners. Physiol Behav. 1996;59(3):44953.

45. Newhouse IJ, Clement DB, Taunton JE, Mckenzie DC. The effects of prelatent/latent iron deficiency on physical work capacity. Med Sci Sports Exerc. 1989;21(3):263-8.

46. Frye AC, Solberg BP, Eichinger MR, Pasche SP. Iron Status In Collegiate Cross Country Runners. Med Sci Sports Exerc. 2008;40(5):S342

47. Polglaze T, Hogan C, Dawson B, et al. Classification of Intensity in Team Sport Activity. Med Sci Sports Exerc. 2018;50(7):1487-1494.

48. Batista MB, Romanzini CLP, Castro-Pinero J, Ronque ERV. Validity of field tests to estimate cardiorespiratory fitness in children and adolescents: a systematic review. Rev Paul Pediatr. 2017;35(2):222-233.

49. Haas JD, Brownlie $4^{\text {th }}$. Iron deficiency and reduced work capacity: A critical review of the research to determine a causal relationship. J Nutr. 2001;131(2):676S-690S

50. Alaunyte I, Stojceska V, Plunkett A, Derbyshire E. Dietary iron intervention using a staple food product for improvement of iron status in female runners. J Int Soc Sports Nutr. 2014;11(1):50.

51. Anschutz S, Rodgers CD, Taylor AW. Meal composition and iron status of experiences male and female distance runners. J Exerc Sci Fit. 2010;8(1):25-33.

52. Castillo MC, Lapieza MG, León F, Nuviala RJ. [Iron intake and pharmacologic supplements in medium and long-distance runners]. Sangre (Barc). 1996;41(3):195-200.

53. Krayenbuehl PA, Battegay E, Breymann C, Furrer J, Schulthess G. Intravenous iron for the treatment of fatigue in nonanemic, premenopausal women with low serum ferritin concentration. Blood. 2011;118(12):3222-7.

54. Burden RJ, Pollock N, Whyte GP, et al. Effect of Intravenous Iron on Aerobic Capacity and Iron Metabolism in Elite Athletes. Med Sci Sports Exerc. 2015;47(7):1399-407. 
55. Chowdhury AD, Longcroft-wheaton G, Davis A, Massey D, Goggin P. Role of faecal occult bloods in the diagnosis of iron deficiency anaemia. Frontline Gastroenterol. 2014;5(4):231-236. doi.org/10.1136/flgastro-2013-100425

56. Duca L, Da ponte A, Cozzi M, et al. Changes in erythropoiesis, iron metabolism and oxidative stress after half-marathon. Intern Emerg Med. 2006;1(1):30-4.

57. Borg $\mathrm{G}$, Linderholm $\mathrm{H}$. Perceived exertion and pulse rate during graded exercise in various age groups. Acta Med Scan. 1967; 194-206.

58. Muyor JM. Exercise Intensity and Validity of the Ratings of Perceived Exertion (Borg and OMNI Scales) in an Indoor Cycling Session. J Hum Kinet. 2013;39:93-101.

59. Whaley MH, Woodall T, Kaminsky LA, Emmett JD. Reliability of perceived exertion during graded exercise testing in apparently healthy adults. J Cardiopulm Rehabil. 1997;17(1):37-42.

60. Haddad M, Stylianides G, Djaoui L, Dellal A, Chamari K. Session-RPE Method for Training Load Monitoring: Validity, Ecological Usefulness, and Influencing Factors. Front Neurosci. 2017;11:612.

61. Martinent G, Decret JC, Isoard-gautheur S, Filaire E, Ferrand C. Evaluations of the psychometric properties of the Recovery-Stress Questionnaire for Athletes among a sample of young French table tennis players. Psychol Rep. 2014;114(2):326-40.

62. Nicolas M, Vacher P, Martinent G, Mourot L. Monitoring stress and recovery states: Structural and external stages of the short version of the RESTQ sport in elite swimmers before championships. J Sport Health Sci. 2019;8(1):77-88. 